PASTOR, Enrique y TORRES, Manuela. "El sistema penitenciario y las personas privadas de libertad en España desde una perspectiva internacional".

Polít. crim. Vol. 12, № 23 (Julio 2017), Art. 5, pp. 124-150.

[http://www.politicacriminal.cl/Vol_12/n_23/Vol12N23A5.pdf]

\title{
El sistema penitenciario y las personas privadas de libertad en España desde una perspectiva internacional
}

\section{The prison system and persons deprived of their liberty in Spain from an international perspective}

\author{
Enrique Pastor Seller \\ Doctor en Sociología. Profesor Titular de Universidad. Universidad de Murcia (España) \\ epastor@um.es \\ Manuela Torres Torres \\ Graduada en Trabajo Social. Departamento de Trabajo social del Centro Penitenciario VI \\ Madrid (España) \\ manuelatorrest@gmail.com
}

\section{Resumen}

El artículo presenta un análisis de la realidad del sistema penitenciario y de la población privada de libertad en España desde una perspectiva comparativa e internacional basado en una extensa investigación sobre la materia, nutrida a partir de diferentes fuentes estadísticas oficiales, contrastadas y solventes. Un análisis detallado de Estados Unidos y los países de la Unión Europea, desde una perspectiva comparativa entre países y de carácter transversal y longitudinal (2000-2015). El texto presenta una amplia descripción de la realidad, así como un análisis comprensivo y causal para discernir la evolución y sentidos de cambio del fenómeno. Los resultados muestran dos realidades penitenciarias muy diferentes, tanto en la actualidad como en la evolución de las mismas: la de Estados Unidos y la de la Unión Europea. En cuanto a España, no mantiene una posición cercana a la de países del Centro de Europa en numerosas variables.

Palabras clave: Privación de libertad, administración de justicia, población reclusa, sistema penitenciario, inserción social.

\begin{abstract}
This article performs an analysis of the prison system and the prison population in Spain, from a comparative and international perspective. It is based on extensive research on the subject, supported from different sources to official statistics that are reviewed and reliable. A detailed analysis of the United States and the Member States of the European Union, from a comparative perspective between countries, as a transversal and long-term perspective (2000-2015). The document shows a wide description of reality, as well as a comprehensive and causal analysis, to discern the evolution and sense of change of the phenomenon. The results reveal opposite prison realities, which differ in both their current situation and their evolution through time: The situation in the United States and in the
\end{abstract}


PASTOR, Enrique y TORRES, Manuela. "El sistema penitenciario y las personas privadas de libertad en España desde una perspectiva internacional".

European Union. Spain's position is not close to that of Central European countries in several variables.

Key words: Imprisonment, administration of justice, prison population, prison system, social inclusion.

\section{Introducción.}

La investigación tiene por objeto analizar el sistema penitenciario y la población privada de libertad en España desde una perspectiva internacional y comparada entre los Estados Unidos (en adelante, EEUU) y la Unión Europea (en adelante, UE), así como entre los diferentes países integrantes de la UE. El estudio se ha realizado desde una perspectiva longitudinal (2000-2015) y transversal, considerando las variables de relevancia en el análisis de la administración penitenciaria y política criminal, en concreto: población reclusa atendiendo a diferentes países en números absolutos y por tasas, distribución por sexo y edad, población extranjera, población preventiva, estancia media, ocupación de prisiones, duración media de las penas y medidas privativas de libertad, distribución territorial, situación procesal-penal, tipología delictiva, clasificación penitenciaria, etc.

Considerando las dimensiones mencionadas anteriormente, la investigación se ha basado en la explotación de estudios y estadísticas oficiales, solventes y contrastadas en el ámbito internacional y nacional. Respecto del análisis de la población privada de libertad en EEUU y Europa, desde una perspectiva comparativa, se han explotado y analizado estudios y estadísticas procedentes del Institute for Criminal Policy Research ${ }^{1}$, Eurostat ${ }^{2}$, Aebi y Delgrande $^{3}$, entre otros. Respecto al análisis de las personas privadas de libertad en España las fuentes utilizadas proceden de investigaciones recientes y contrastadas sobre la materia ${ }^{4}$, así como las propias del Instituto Nacional de Estadística ${ }^{5}$ (en adelante INE), la estadística oficial nacional de población penitenciaria que publica la Secretaría General de

1 INSTITUTE FOR CRIMINAL POLICY RESEARCH. World Prison Brief. 2016. En: http://www.prisonstudies.org/world-prison-brief [visitado el 27.02.2016].

${ }_{2}$ EUROSTAT. Estadísticas de población. 2016, en: http://ec.europa.eu/eurostat/statisticsexplained/index.php/Population_statistics_at_regional_level/es. [visitado el 28.02.2016].

${ }^{3}$ Estudios que periódicamente son publicados por AEBI, Marcelo F., y DELGRANDE, Natalia SPACE ICouncil of Europe Annual Penal Statistics: Prison Population. 2015, en: http://wp.unil.ch/space/files/2015/02/SPACE-I-2013-English.pdf, [visitado el 20.01.2016].

${ }^{4}$ Entre otros FACAL FONDO, Teresa. "Contextualización del trabajo social penitenciario: situación actual", Revista de Servicios Sociales y Política Social, no 109 (2015) pp.11-20; PASTOR SELLER, Enrique; TORRES TORRES, Manuela, "La población reclusa en España", en: PASTOR SELLER, Enrique; CANO SORIANO, Leticia (Coords.), Políticas e intervenciones ante los procesos de vulnerabilidad y exclusión social de personas y territorios: análisis comparado México-España. Madrid (España): Dykinson y México: UNAM, 2016, pp. 225-244; GEA, María José, "Género, encierro y maternidad. Un acercamiento a la prisión en femenino", Revista de Servicios Sociales y Política Social, no 109 (2015), pp. 51-62.

5 Estadísticas explotadas y analizadas de las propias publicadas por el INSTITUTO NACIONAL DE ESTADÍSTICA. Población reclusa hasta 2014.2 (2015a), en: http://www.ine.es/jaxi/tabla.do?path=/t18/a052/a1998/10/\&file=j10050.px\&type=pcaxis\&L=0, [visitado el 10.02.2016]. El INE es el organismo oficial estatal encargado de sistema estadístico en España. 
Polít. crim. Vol. 12, № 23 (Julio 2017), Art. 5, pp. 124-150.

[http://www.politicacriminal.cl/Vol_12/n_23/Vol12N23A5.pdf]

Instituciones Penitenciarias (Ministerio del Interior $^{6}$ ). En cuanto a Cataluña se han utilizado las estadísticas oficiales de la Generalitat de Cataluña ${ }^{7}$, dado que esta Comunidad Autónoma tiene transferidas las competencias en materia penitenciaria desde 1984 (debe someterse a la Ley Orgánica General Penitenciaria ${ }^{8}$-en adelante, LOGP- aunque cuenta con un Reglamento propio de desarrollo de la citada ley).

El artículo se estructura del siguiente modo. En primer lugar, se presenta el sistema penitenciario en España desde una perspectiva histórica y en relación con el contexto social, la normativa y los organismos y administraciones responsables de la política penitenciaria. A continuación, se analiza la población privada de libertad y los centros y servicios de la administración penitenciaria en España. Seguidamente, se exponen los resultados de la investigación referida a EEUU y los países de la UE desde una perspectiva comparativa entre países. Tras la exposición de los resultados de la investigación se presenta un análisis de los datos obtenidos de manera comparativa con otros estudios e investigaciones sobre la materia identificando elementos de análisis y correlación con el contexto social desde una perspectiva longitudinal. Finalmente se presentan las conclusiones y propuestas que se alcanzan tras el citado análisis.

\section{El sistema penitenciario en España.}

A lo largo de la historia cada sociedad ha reprochado las conductas "antisociales" de sus miembros de formas muy diversas, sancionando con la descuartización, crucifixión, lapidación, mutilación, trabajos forzados, expatriación y multas, entre otras, hasta llegar al encarcelamiento, primero a la espera de juicio o para asegurar el pago de la multa o deuda $\mathrm{y}$, finalmente, como medio de retención y aislamiento de los delincuentes del resto de la sociedad, ya en el siglo $\mathrm{XVI}^{9}$.

Las penas privativas de libertad son actualmente la base del sistema penal de los pueblos modernos. Se definen, como aquellas que privan al penado de su libertad internándolo en un establecimiento penitenciario, en el que permanecerá durante un tiempo determinado, sometido a un régimen de vida y tratamiento regulado previamente. La pena privativa de libertad "es el resultado de una evolución racionalizadora y humanitaria del Derecho punitivo" $"$.

\footnotetext{
${ }^{6}$ Estadísticas y estudios de carácter especializado y específico sobre la materia publicados por el MINISTERIO DEL INTERIOR. Estadística penitenciaria. (2016a), en: http://www.institucionpenitenciaria.es/web/portal/documentos, [visitado el 23.02.2016].

GENERALITAT DE CATALUNYA. Centres penitenciaris. 2016, en: http://justicia.gencat.cat/ca/ambits/reinsercio_i_serveis_penitenciaris/serveis_penitenciaris/els_centres_penite nciaris, [visitado el 22.02.2016].

${ }^{8}$ ESPAÑA. Ley Orgánica 1/1979, de 26 de septiembre, General Penitenciaria, Boletín Oficial del Estado, ${ }^{\circ}$ 239 de 5 de octubre de 1979 (1979), pp. 23180-23186.

${ }^{9}$ Como refiere GUDÍN RODRÍGUEZ-MAGARIÑOS, Faustino, "Introducción". En GARCÍA VALDÉS, C. (Dir.), Historia de la prisión. Teorías Economicistas: Crítica. Madrid: Edisofer, 1997, pp.1-47.

${ }^{10}$ LEGANÉS GÓMEZ, Santiago, La Evolución de la clasificación penitenciaria, Madrid: Ministerio del Interior, 2005, p. 17.
} 
PASTOR, Enrique y TORRES, Manuela. "El sistema penitenciario y las personas privadas de libertad en España desde una perspectiva internacional".

La actividad de la Administración Penitenciaria en España se desarrolla en base a lo recogido en el Art. 25.2 de la Constitución Española de 1978:

"Las penas privativas de libertad y las medidas de seguridad estarán orientadas hacia la reeducación y reinserción social (...). El condenado a pena de prisión que estuviere cumpliendo la misma gozará de los derechos fundamentales de este Capítulo, a excepción de los que se vean expresamente limitados por el contenido del fallo condenatorio, el sentido de la pena y la ley penitenciaria"11.

A partir de este mandato constitucional se establece el ordenamiento jurídico español que regula el sistema penitenciario, concretamente la $\mathrm{LOPG}^{12}$, el Código Penal ${ }^{13}$ y el Reglamento Penitenciario ${ }^{14}$.

El sistema penitenciario español está basado en el denominado sistema de individualización científica recogido en el Art. 72 de la LOGP, donde se establece que

"las penas privativas de libertad se ejecutarán según el sistema de individualización científica, separado en grados, el último de los cuales será la libertad condicional (...) Siempre que (...) un interno resulte estar en condiciones para ello, podrá ser situado inicialmente en grado superior, salvo el de libertad condicional"15.

El sistema es progresivo y flexible, siendo el tratamiento su eje central; la LOGP lo define en su Art. 59:

"Consiste en el conjunto de actividades directamente dirigidas a la consecución de la reeducación y reinserción social de los penados [...] pretende hacer del interno una persona con la intención y la capacidad de vivir respetando la Ley penal, así como de subvenir a sus necesidades" ${ }^{\prime 16}$.

El Real Decreto 190/1996 ${ }^{17}$ aprueba el Reglamento de desarrollo y ejecución de la LOGP, establece la voluntariedad del tratamiento y la necesidad de estimular la participación de la persona recogiendo una concepción más amplia del tratamiento, considerándolo un proceso de formación integral de la personalidad del penado, dotándolo de instrumentos eficaces

${ }^{11}$ ESPAÑA. Constitución Española, Boletín Oficial del Estado, no ${ }^{\circ} .311$, de 29 de diciembre de 1978 (1978), pp. 29313-19424, p. 29318.

${ }^{12}$ ESPAÑA. LOGP, cit. nota $\mathrm{n}^{\circ} 8$.

${ }^{13}$ ESPAÑA. Ley Orgánica 10/1995, de 23 de noviembre, del Código Penal, Boletín Oficial del Estado, no 281, de 24 de noviembre de 1995 (1995), pp. 33987-34058.

${ }^{14}$ ESPAÑA. Real Decreto 190/1996, de 9 de febrero, por el que se aprueba el Reglamento Penitenciario, Boletín Oficial del Estado, no 40, de 15 de febrero de 1996 (1996), pp. 5380-5435.

${ }^{15}$ ESPAÑA. LOGP, cit. nota $n^{\circ}$ 8, p. 23185.

${ }^{16}$ ESPAÑA. LOGP, cit. nota ${ }^{\circ}$ 8, p. 23184.

${ }^{17}$ El texto incorpora las modificaciones derivadas de la entrada en vigor en mayo de 1996 del Código Penal en ESPAÑA. Ley 10/1995, cit. nota $n^{\circ} 13$ y los cambios en la composición y características de la población reclusa. Concretamente: una mayor presencia de mujeres y reclusos extranjeros, el envejecimiento en términos demográficos, la variación del perfil sociológico o la aparición de nuevas patologías con especial incidencia en la población reclusa). Recoge, a su vez, los avances en la intervención y el tratamiento de las personas internas, con especial referencia a su vertiente resocializador, en sintonía con FACAL, "Contextualización", cit. nota n 4, p. 14. 
Polít. crim. Vol. 12, № 23 (Julio 2017), Art. 5, pp. 124-150.

[http://www.politicacriminal.cl/Vol_12/n_23/Vol12N23A5.pdf]

para la vida en libertad ${ }^{18}$. Esta misma norma encomienda en su Art. 111 a las Juntas de Tratamiento las tareas de observación, clasificación y tratamiento penitenciario, cuyas decisiones serán ejecutadas por los Equipos técnicos.

La clasificación de un penado consiste en la definición del marco jurídico y regimental que se le va aplicar durante el cumplimiento de la pena y en el que va a tener lugar el tratamiento resocializador. Se trata de un procedimiento de asignación de un grado de tratamiento y del programa individualizado de tratamiento correspondiente en función de las características que presente dicho penado. Este estudio se realiza por primera vez, como máximo dos meses después de la recepción en el centro penitenciario del testimonio de sentencia y la liquidación de condena del penado. Se revisa como máximo cada seis meses, exceptuando la clasificación en primer grado, que se revisa cada tres meses.

Los grados de tratamiento que contempla la LOGP son tres, primer, segundo y tercer grado. El primer grado, consiste en un régimen de vida cerrado, se aplica a personas penadas extremadamente peligrosas o manifiestamente inadaptadas a los otros regímenes. La aplicación de este grado debe ser excepcional, es decir sólo cuando no existan otros mecanismos disponibles que permitan la adaptación de la persona penada y previamente debe haberse descartado la existencia de alguna patología psiquiátrica, grave. El segundo grado se corresponde con un régimen de vida ordinario y se aplicará a las personas penadas que presenten unas circunstancias de normal convivencia aunque, sin capacidad para vivir por el momento en semi-libertad. El tercer grado corresponde a un régimen de vida en semi-libertad, que se aplicará a aquellas personas penadas capacitadas para ello. Se trata de un régimen que permite salidas para realizar actividades, ya sean laborales o tratamentales, dirigidas a la reeducación y reinserción social, así como a disfrutar salidas de fin de semana y permisos ordinarios ${ }^{19}$.

En la configuración del sistema penitenciario en España cabe destacar el Real Decreto $840 / 2011^{20}$ por el que se establecen las circunstancias de ejecución de las penas de trabajos en beneficio de la comunidad y de localización permanente en centros penitenciarios. Este Real Decreto establece las circunstancias de ejecución de las posibilidades contempladas en el vigente Código Penal como alternativas al ingreso en prisión: pena de trabajo en beneficio de la comunidad, suspensiones de condena y sustituciones de condena. Con éstas medidas se pretende evitar los efectos desocializadores de la privación de libertad. La última reforma del Código Penal, llevada a cabo por la Ley Orgánica $1 / 2015^{21}$, afecta a

\footnotetext{
${ }^{18}$ En coincidencia con BUENO ARÚS, Francisco, "Novedades en el concepto de tratamiento penitenciario", Revista de Estudios Penitenciarios, no 252 (2006), pp. 9-36.

19 Como señala ARANDA CARBONELL, María José, "Una aproximación práctica a la clasificación penitenciaria", Revista de Estudios Penitenciarios, no 252 (2006), pp. 37-76.

${ }^{20}$ ESPAÑA. Real Decreto 840/2011, de 17 de junio, por el que se establecen las circunstancias de ejecución de las penas de trabajo en beneficio de la comunidad y de localización permanente en centro penitenciario, de determinadas medidas de seguridad, así como de la suspensión de la ejecución de las penas privativas de libertad y sustitución de penas, Boletín Oficial del Estado, nº 145, de 18 de junio de 2011 (2011), pp. 6293362941.

${ }^{21}$ ESPAÑA. Ley Orgánica 1/2015, de 30 de marzo, por la que modifica la ley Orgánica 10/1995, de 23 de noviembre, del Código Penal, Boletín Oficial del Estado, no 77, de 31 de marzo de 2015 (2015a), pp.2706127176.
} 
PASTOR, Enrique y TORRES, Manuela. "El sistema penitenciario y las personas privadas de libertad en España desde una perspectiva internacional".

ámbitos muy diversos, pero en lo que respecta al cumplimiento de la condena, las principales reformas que introduce son las siguientes:

a) Posibilidad de clasificación directa a tercer grado por motivos humanitarios y de dignidad personal de penados enfermos muy graves con padecimientos incurables y de los septuagenarios sometidos a periodo de seguridad o prisión permanente revisable (para el resto de penas no existe ningún impedimento para clasificar inicialmente en tercer grado, ya sea por motivos humanitarios o no), valorando especialmente su escasa peligrosidad (Art. 36.3) cuya valoración se realizará por las Juntas de Tratamiento a petición de las autoridades judiciales.

b) Modificación del régimen de suspensión de la ejecución de las penas privativas de libertad recogidas en los $\operatorname{Art}[\mathrm{s}] 80$ a 87.

c) Sustitución de la ejecución de la pena de prisión por la expulsión del territorio nacional para ciudadanos extranjeros, siendo norma general para las penas superiores a un año (Art. 89).

d) Introducción de una nueva modalidad de adelantamiento de la libertad condicional bajo determinadas circunstancias. Supone una importante transformación de esta figura, configurándola como un supuesto de suspensión de la ejecución de las penas privativas de libertad y no como el último grado de clasificación previsto en el Art. $72.1 \mathrm{de}$ la LOGP. (Art[s] 90, 91 y 92).

e) Incorporación de la modalidad punitiva de prisión permanente revisable.

La Secretaría General de Instituciones Penitenciarias ${ }^{22}$ señala los objetivos y principios que inspiran el régimen penitenciario español actualmente. En cuanto a los primeros, la actividad penitenciaria está encaminada a garantizar el cumplimiento de las penas privativas de libertad, custodiar a los reclusos y proteger su integridad; capacitar a las personas internas para una vida en libertad respetando el cumpliendo la ley, las normas sociales y poner en manos de éstos los instrumentos, tanto laborales como educativos que les permitan enfrentarse con éxito a la vida en libertad. Para alcanzar estos objetivos la actividad penitenciaria debe ajustarse a los principios de: individualización, progresión de grado, tratamiento penitenciario, cumplimiento de la condena en un lugar próximo a su lugar de residencia y relaciones con el exterior (comunicaciones y permisos de salida).

\section{Tipología de establecimientos y servicios de la administración penitenciaria en España.}

Los establecimientos penitenciarios se encuentran concebidos arquitectónicamente como un núcleo urbano independiente, que permite la separación interior y la clasificación penitenciaria de la población que alberga. En ellos desempeñan su labor los profesionales penitenciarios; garantizando, a su vez, la seguridad y la custodia de las personas internas ${ }^{23}$. Actualmente podemos distinguir diferentes modalidades de centros dependientes del Ministerio del Interior a través de la Secretaría General de Instituciones penitenciarias:

\footnotetext{
${ }^{22}$ SECRETARÍA GENERAL DE INSTITUCIONES PENITENCIARIAS, El Sistema Penitenciario Español, Madrid, España: Ministerio del Interior, 2014.

${ }_{23}$ MINISTERIO DEL INTERIOR. Centros penitenciarios. (2016b), en: http://www.institucionpenitenciaria.es/web/portal/centrosPenitenciarios, [visitado el 20.02.2016].
} 
Polít. crim. Vol. 12, No 23 (Julio 2017), Art. 5, pp. 124-150.

[http://www.politicacriminal.cl/Vol_12/n_23/Vol12N23A5.pdf]

Centros penitenciarios, para el cumplimiento de penas, medidas de seguridad y prisiones preventivas. Regularmente son de régimen ordinario, aunque también existen de régimen cerrado.

Centros de Inserción social (en adelante, CIS), destinados al cumplimiento de penas en régimen abierto y al seguimiento de liberados condicionales

Unidades externas de madres, para mujeres que cumplen condena en compañía de sus hijos/as menores de 3 años. Diseñadas con la finalidad de que los menores vivan en un ambiente diferente al que representa la prisión y así favorecer su educación.

Centros Psiquiátricos penitenciarios, dedicados a la custodia y el tratamiento de las personas que se encuentran internas en ellos por decisión de los Tribunales de Justicia.

Unidades dependientes, se trata de viviendas o pisos ubicados fuera de los centros penitenciarios aunque dependientes de éstos. Son de régimen abierto y en su funcionamiento suelen colaborar organizaciones no gubernamentales, fundaciones y asociaciones.

Servicios de gestión de penas y medidas alternativas, no se trata de centros donde cumplir condena, sino de unidades administrativas a las que les corresponde la gestión de penas privativas de derechos y de medidas alternativas al ingreso en prisión. Normalmente suelen estar integradas en los CIS.

Actualmente la Administración General del Estado cuenta con 68 centros penitenciarios, 2 centros psiquiátricos penitenciarios, 13 centros de inserción social autónomos y otros 19 dependientes de centros penitenciarios, 3 unidades externas de madres (Madrid, Sevilla y Palma de Mallorca) y 55 servicios de gestión de penas y medidas alternativas. Destacar que existen unidades internas o módulos de madres en los centros penitenciarios, concretamente tres: Sevilla (C.P. Alcalá de Guadaira), Valencia (C.P. Picassent), Madrid (C.P. Madrid VI - C.P. Aranjuez).

La Generalitat de Cataluña ${ }^{24}$ cuenta con 10 centros penitenciarios, 5 centros de inserción social denominados "centre penitenciari obert", un centro psiquiátrico penitenciario denominado "pavelló hospitalari penitenciari" 25 y unidades de madres.

Dependiente del Ministerio de Defensa, un Establecimiento penitenciario militar, para el cumplimiento de penas de personas que se caracterizan por pertenecer o haber pertenecido

\footnotetext{
${ }^{24} \mathrm{La}$ Comunidad Autónoma de Cataluña tiene transferidas las competencias en materia penitenciaria por la Administración General del Estado de España desde 1984, y aunque tiene que someterse a la Ley Orgánica General Penitenciaria en esta materia, cuenta con un Reglamento propio de desarrollo de la citada ley.

${ }^{25}$ Análisis realizados a partir de fuentes procedentes de GENERALITAT DE CATALUNYA. $\operatorname{cit}$ nota $n^{\circ} 7$.
} 
PASTOR, Enrique y TORRES, Manuela. "El sistema penitenciario y las personas privadas de libertad en España desde una perspectiva internacional".

al ejército o a la guardia civil ${ }^{26}$. Dichos centros se encuentran regulados de manera específica por el Real Decreto 1396/1992, de 20 de noviembre de 1992 ${ }^{27}$.

\section{Análisis de la realidad de la población reclusa en España.}

\subsection{Caracterización socio-demográfica.}

La población reclusa en España a 31 de diciembre de 2015 era de 61.614 personas, $(0.132 \%$ de la población de España situada en 46.423.064 habitantes), de las que 56.592 (92.35\%) son hombres y 4.722 (7.65\%) mujeres. En cuanto a la edad, el grupo menos numeroso es el comprendido entre los 18 y los 20 años, seguido de mayores de 60 años; destacando los grupos de 41 a 60 años y 31 a 40 años. En cuanto a población reclusa extranjera, en 2015 ascendía a 17.870 personas, que representan el $29 \%$ de la población reclusa; el 92,41\% son hombres y el 7,59\% mujeres.

\subsection{Análisis longitudinal.}

El análisis de la evolución de la población reclusa en España durante el período comprendido entre 2000 y 2015 constata un incremento progresivo hasta el año 2009, donde alcanza las 76.079 personas y un descenso desde esa fecha, llegando a 61.614 en el año 2015.

Figura 1: Evolución de la población reclusa en España (2000-2015)

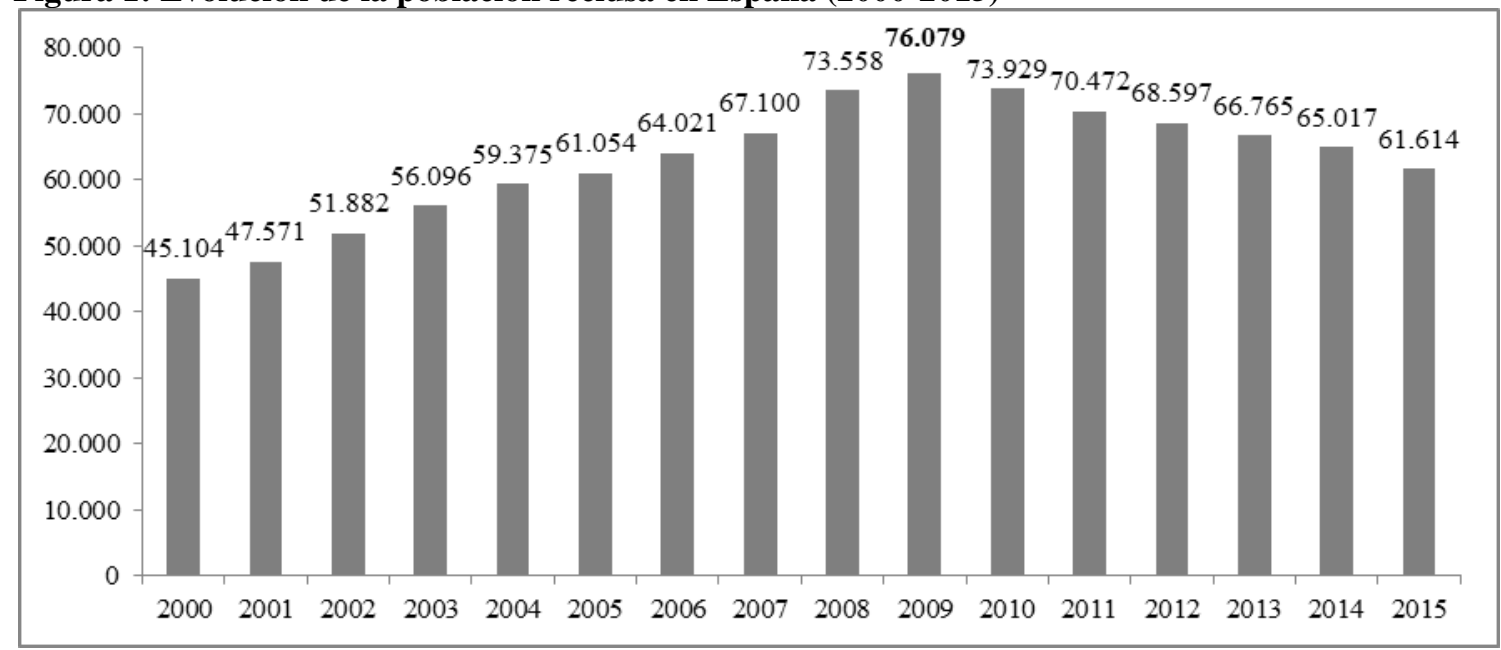

Fuente: Elaboración propia a partir de diferentes estadísticas procedentes de Instituto Nacional de Estadística y Ministerio del Interior.

\footnotetext{
${ }^{26} \mathrm{Al}$ respecto resulta de interés la investigación sobre este tipo de establecimientos realizada por SANCHEZ PEREZ, Francisca D. y PASTOR SELLER, Enrique, "Trabajo social penitenciario: prisión civil "vs" prisión militar", Revista de Servicios Sociales y Política Social, n 109 (2015), pp.73-89.

${ }^{27}$ Los Establecimientos Penitenciarios Militares se encuentran regulados de manera específica por Real Decreto 1396/1992, de 20 de noviembre, por el que se aprueba el Reglamento de Establecimientos Penitenciarios Militares. Boletín Oficial del Estado, no 305, de 21 de diciembre de 1992 (1992), pp.43288 43292 .
} 
Polít. crim. Vol. 12, No 23 (Julio 2017), Art. 5, pp. 124-150.

[http://www.politicacriminal.cl/Vol_12/n_23/Vol12N23A5.pdf]

Tras analizar las tasas anuales de población reclusa por cada 100.000 habitantes en dicho periodo, se deduce que la evolución de la población reclusa no se corresponde con la evolución demográfica de la población, ya que la tasa de población reclusa en España ha aumentado considerablemente en el período comprendido entre 2000 y 2009, pasando de 111 personas/100.000 h en el año 2000 a 163 en el 2009, bajando paulatinamente a partir de esa fecha, 2010 (157), 2011 (150), 2012 (147), 2013 (143), 2014 (139) y situándose en 133 en 2015 .

Figura 2: Evolución de la Tasa de población reclusa por 100.000h en España (2000-2015)

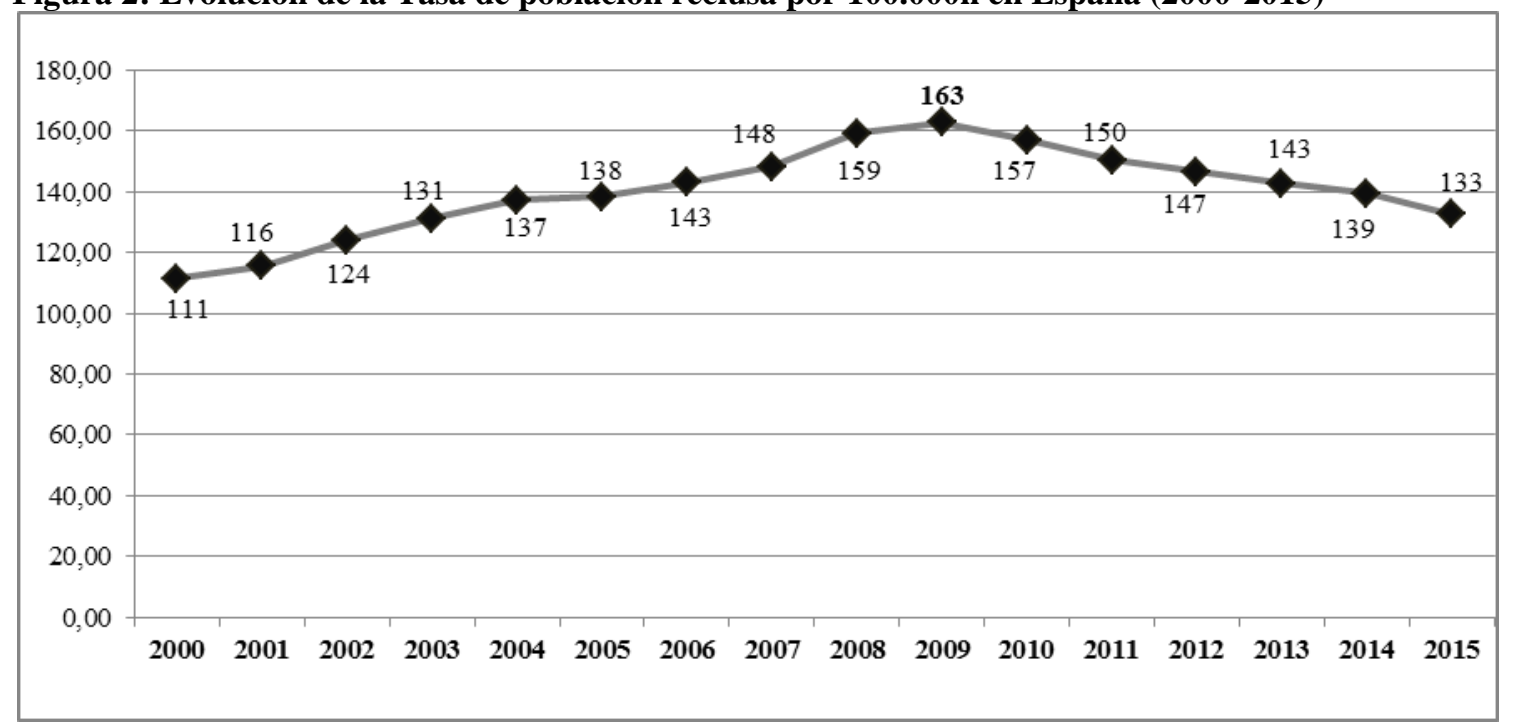

Fuente: Elaboración propia.

\subsection{Distribución geográfica.}

En términos absolutos la Comunidad Autónoma que registra más población en situación de privación de libertad es Andalucía (23,30\%), seguida de Cataluña (14,31\%) y Madrid $(13,44 \%)$. Sin embargo, relacionando estos datos con la población de cada Comunidad Autónoma, la Ciudad Autónoma de Melilla con 305 personas reclusas/100.000 habitantes casi triplica la media nacional (situada en 133 personas reclusas/100.000 habitantes), seguida de Ceuta con 225. También con valores superiores a la media nacional, concretamente entre 171 y 135, se encuentran: Castilla-León, Andalucía, Canarias, Baleares, Aragón y la Comunidad Valenciana. En el lado opuesto, con medias muy inferiores a la nacional, se sitúan: Navarra con 48, País Vasco con 58 y Castilla-La Mancha con 87. Con una media muy similar a la nacional se encuentran Extremadura, La Rioja, Murcia, Cataluña, Cantabria, Asturias, Madrid y Galicia ${ }^{28}$.

\footnotetext{
${ }^{28}$ Puede ampliarse esta información en PASTOR SELLER, La población reclusa, cit. nota ${ }^{\circ} 4$.
} 
PASTOR, Enrique y TORRES, Manuela. "El sistema penitenciario y las personas privadas de libertad en España desde una perspectiva internacional".

Figura 3: Distribución por Comunidades Autónomas de la población reclusa en España (2015)

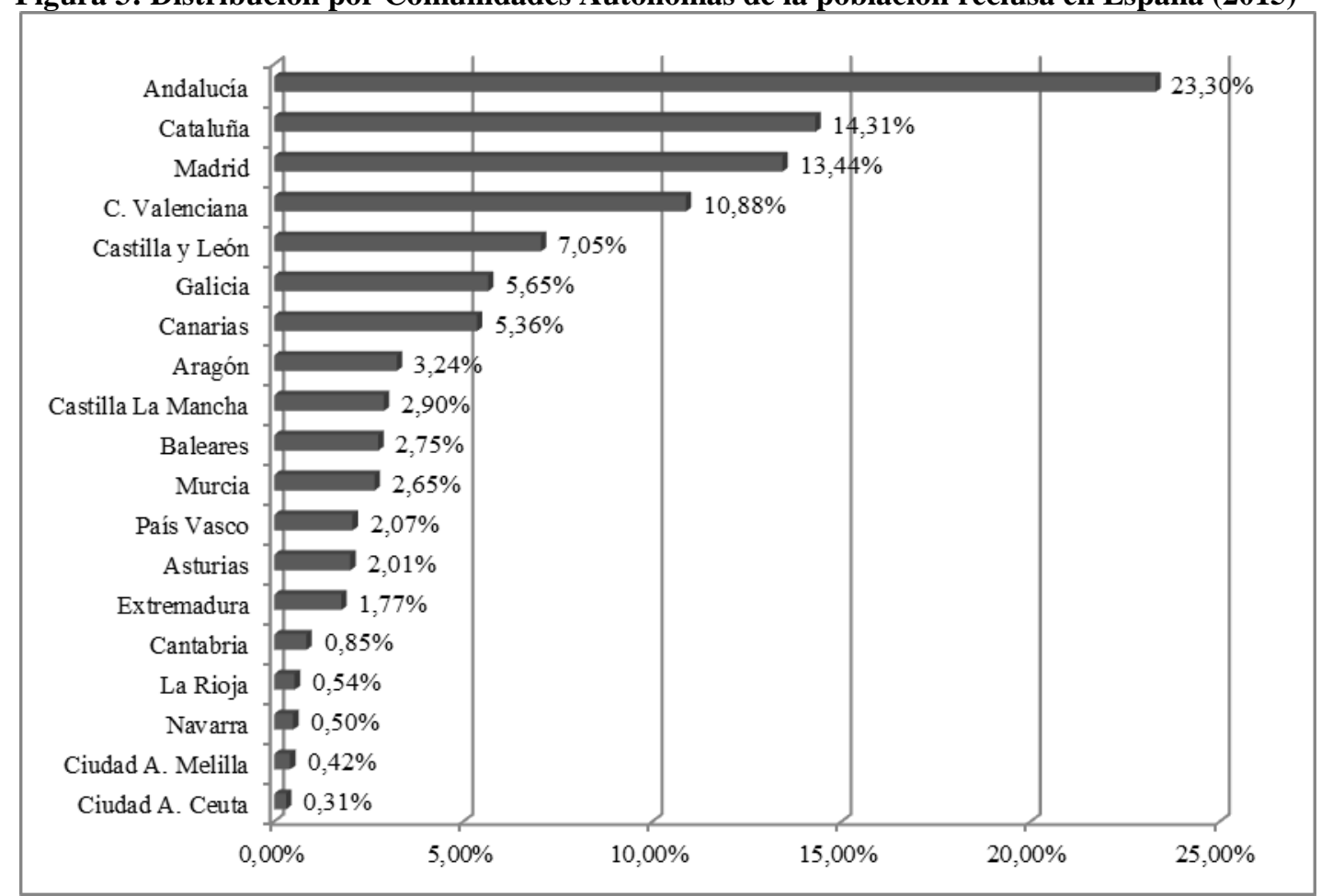

Fuente: Elaboración propia.

\subsection{Situación procesal-penal.}

En cuanto a la situación procesal-penal, en sintonía con estudios sobre la materia ${ }^{29}$, la mayor parte de la población reclusa, hombres o mujeres, se encuentra está penada $(86,36 \%)$, seguida de la que se encuentra en situación de prisión preventiva $(12,59 \%)$ y por último, en un número muy inferior, están las personas penadas preventivas $(1,05 \%)$. Estas cifras se complementan con 577 personas más, penadas, pero que se encuentran cumpliendo una medida de seguridad ${ }^{30}$, de los que 546 son hombres y 31 mujeres. Las medidas de seguridad que se ejecutan en establecimientos penitenciarios, se llevan a cabo fundamentalmente en psiquiátricos penitenciarios $\mathrm{y}$, en algunos casos, en centros penitenciarios. La forma de cumplimiento de estas penas es diferente a la de las penas privativas de libertad y se encuentra regulada en el Capítulo VII del Título VII del Reglamento Penitenciario ${ }^{31}$ y en el Real Decreto $840 / 2011$, de 17 de junio $^{32}$, por el que se establecen las circunstancias de ejecución de las penas de trabajo en beneficio de la comunidad y de localización permanente en centro penitenciario, de determinadas medidas

\footnotetext{
${ }^{29}$ Según estudios recientes de PASTOR SELLER/TORRES TORRES, "La población reclusa”, cit. nota n 4.

${ }^{30}$ Un Juzgado o tribunal puede condenar a una persona a una medida de seguridad cuando consideren que se dan circunstancias de anomalía o alteración psíquica, intoxicación plena por consumo de alcohol, drogas tóxicas, estupefacientes, sustancias psicotrópicas u otras de efectos similares, o que por sufrir alteraciones de la percepción desde el nacimiento o la infancia, tengan alterada gravemente la conciencia de la realidad, circunstancias que le impedirían comprender la ilicitud del hecho o actuar conforme a ese comprensión. Las medidas de seguridad pueden ser privativas de libertad y no privativas de libertad. El internamiento en un centro psiquiátrico es una de las mediad de seguridad privativas de libertad que contempla el Código Penal

${ }^{31}$ ESPAÑA. Real Decreto 190/1996, cit. nota ${ }^{\circ} 14$.

${ }^{32}$ ESPAÑA. Real Decreto 840/2011, cit. nota $n^{\circ} 20$.
} 
Polít. crim. Vol. 12, No 23 (Julio 2017), Art. 5, pp. 124-150.

[http://www.politicacriminal.cl/Vol_12/n_23/Vol12N23A5.pdf]

de seguridad, así como de la suspensión de la ejecución de la penas privativas de libertad y sustitución de penas.

\subsection{Análisis de la tipología delictiva y clasificación penitenciaria.}

En cuanto a la tipología delictiva aún contamos con una exigua población reclusa que cumple condena por delitos penados por el Código Penal Derogado, el 0,43\% de penados, principalmente por delitos contra las personas y contra la propiedad. El 99,57\% restante cumplen penas por el Código Penal vigente ${ }^{33}$, es decir, los hechos delictivos fueron cometidos a partir de mayo de 1996, o se produjo una revisión posterior de la sentencia con la aplicación de esta nueva legislación por ser más beneficiosa. En este caso, en coincidencia con investigaciones recientes ${ }^{34}$, podemos observar en la figura 4 que los delitos por los que más hombres se encuentran cumpliendo condena son contra el patrimonio y el orden socioeconómico con un 38,81\% y contra la salud pública con un 21,39\%; seguidos por los delitos de violencia de género, pero con un porcentaje mucho menor, el $7,93 \%$, por los homicidios $(7,46 \%)$ y por delitos contra la libertad sexual con el $6,30 \%$. En el caso de las mujeres, el 38,84\% cumplen condenas por delitos contra la salud pública, el 34,61\% contra el patrimonio y el orden socioeconómico, en porcentajes mucho menores, por delitos de homicidio y sus formas el 7,46\% y por lesiones en el $4.70 \%$.

Figura 4: Tipología delictiva por sexo en 2015.

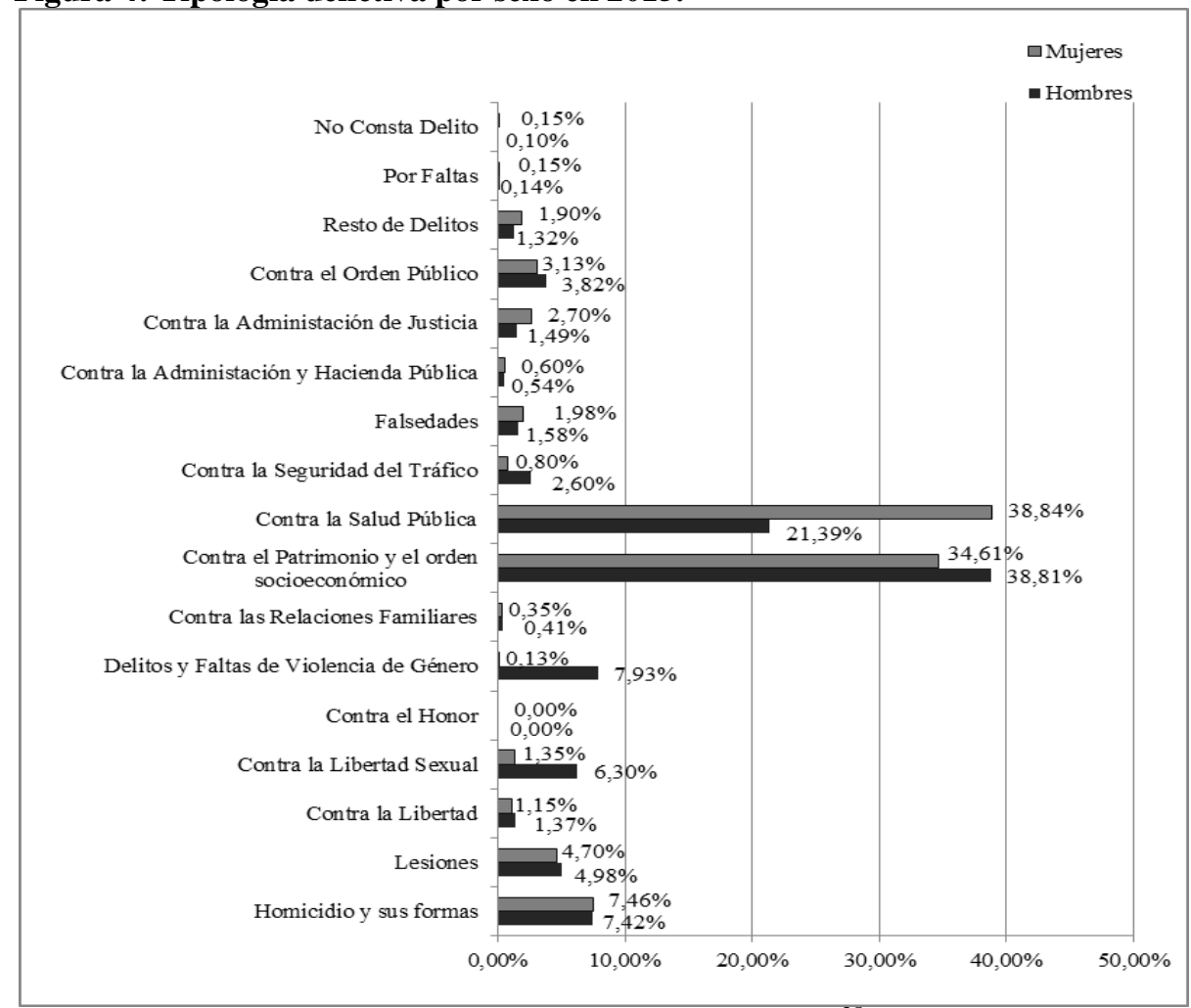

Fuente: Elaboración propia a partir de Ministerio del Interior ${ }^{35}$.

\footnotetext{
${ }^{33}$ ESPAÑA. Ley Orgánica 10/1995, Código Penal, cit. nota no 13.

${ }^{34}$ PASTOR SELLER/TORRES TORRES, "La población reclusa", cit. nota no 4.

${ }^{35}$ MINISTERIO DEL INTERIOR, cit. nota $n^{\circ} 5$.
} 
PASTOR, Enrique y TORRES, Manuela. "El sistema penitenciario y las personas privadas de libertad en España desde una perspectiva internacional".

Del análisis de la evolución de la clasificación penitenciaria de la población penada de 2005 a 2015 podemos constatar que permanece estable en el tiempo y en la que el grado por excelencia es el segundo, con una media de aplicación cinco veces superior al tercer grado, que evoluciona del siguiente modo: $13,34 \%$ en 2005 . 16,89\% en 2011 y $15,43 \%$ en 2015 . El descenso de clasificados en primer grado de 2005 a 2015 es moderado.

Figura 5: Evolución de la clasificación penitenciaria (2005-2015)

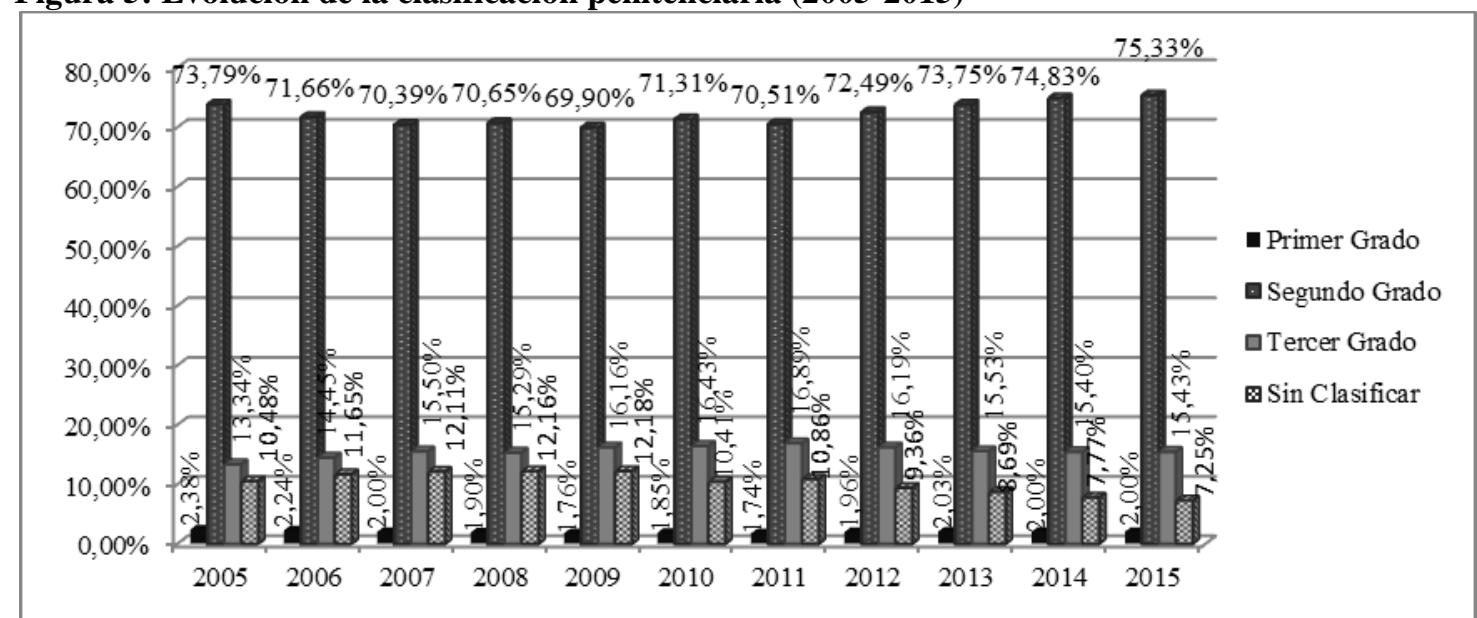

Fuente: Elaboración propia a partir de Ministerio del Interior ${ }^{36}$.

\section{La realidad penitenciaria en Europa y Estados Unidos.}

\subsection{Población reclusa.}

EEUU con más 321 millones de habitantes ${ }^{37}$ y la UE con más de $507^{38}$, presentan cifras de población reclusa muy diferentes: EEUU con 2.217.000 personas reclusas y en el caso de la UE con $578.917^{39}$.

\footnotetext{
${ }^{36}$ MINISTERIO DEL INTERIOR, cit. nota $\mathrm{n}^{\circ} 6$.

37 Según datos de Expansión, En: http://www.datosmacro.com/demografia/poblacion/usa, [visitado el 28.02.2016].

${ }^{38}$ Según datos de EUROSTAT. cit. nota $n^{\circ} 2$, en http://ec.europa.eu/eurostat/statisticsexplained/index.php/Population_statistics_at_regional_level/es. [visitado el 28.02.2016].

${ }^{39}$ Según explotaciones procedentes de INSTITUTE FOR CRIMINAL POLICY RESEARCH, World Prison Brief, 2016, cit. nota n $\mathrm{n}^{\mathrm{T}}$ 1, en: http://www.prisonstudies.org/world-prison-brief, [visitado el 27.02.2016].
} 
Polít. crim. Vol. 12, No 23 (Julio 2017), Art. 5, pp. 124-150.

[http://www.politicacriminal.cl/Vol_12/n_23/Vol12N23A5.pdf]

Figura 6: Población reclusa en EEUU y países de la UE

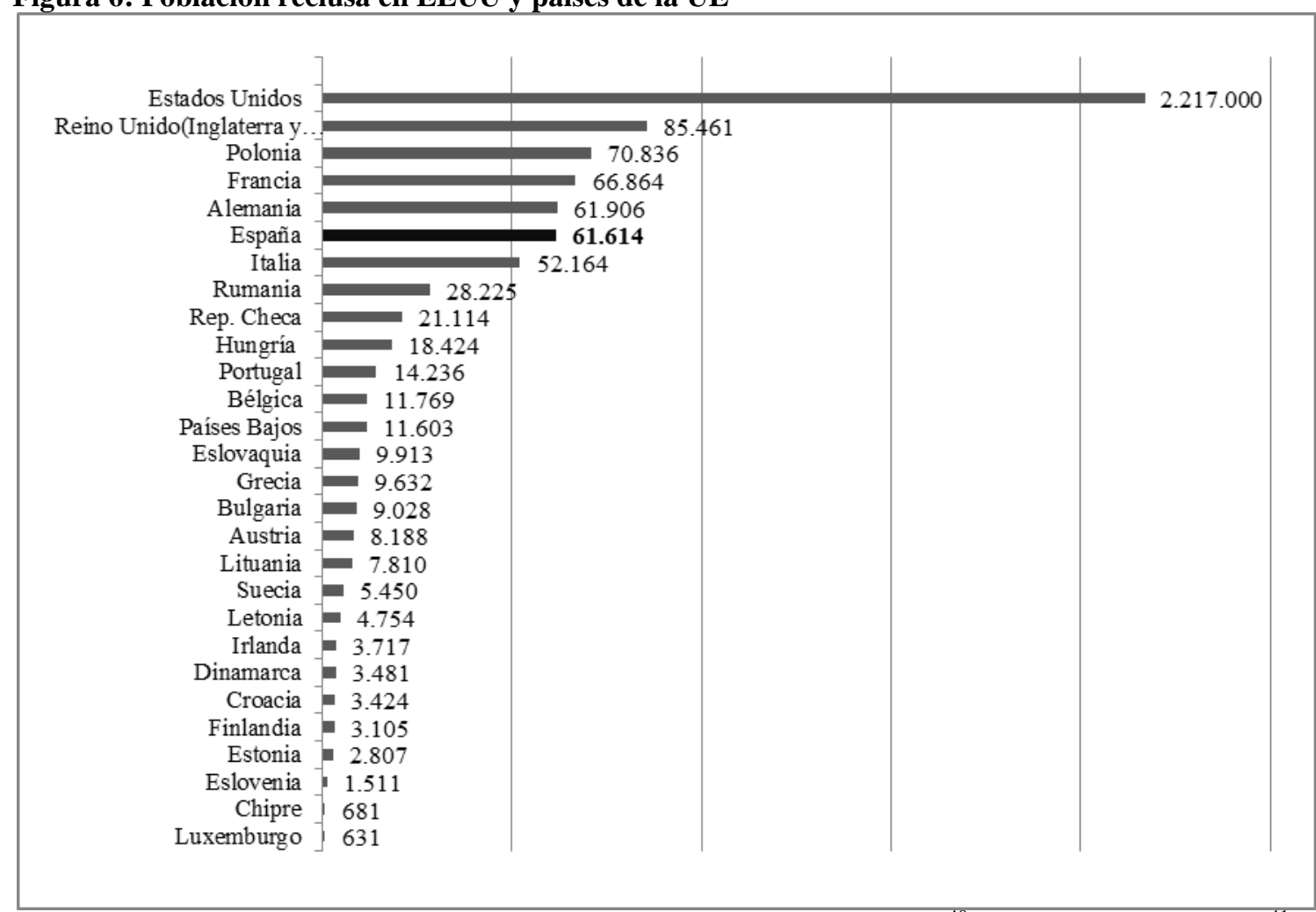

Fuente: Elaboración propia a partir de Institute for Criminal Policy Research ${ }^{40}$ y Ministerio del Interior ${ }^{41}$

Como podemos constatar de la figura anterior, la población reclusa según los distintos países, oscilando en la UE entre las 85.461 del Reino Unido y las 631 de Luxemburgo. España, con 61.614, es el quinto país con mayor población reclusa de la UE, sólo superada por Reino Unido, Polonia, Francia y Alemania. En el extremo nos encontramos con Luxemburgo, Chipre, y Eslovenia.

Trasladando estas cifras de población reclusa a tasa por habitante (población reclusa por 100.000 habitantes), podemos observar en la figura siguiente (7), que EEUU con 698 personas, duplica la tasa de población reclusa de Lituania, (país europeo con mayor tasa), quintuplicando la tasa media de población reclusa de la UE, situada en 125.5 personas. En cuanto a los países europeos, subrayar las altas tasas de Lituania (268), Letonia (239) y Estonia (214), seguidos por la República Checa, Hungría, Polonia y Eslovaquia, con tasas entre 200 y 180, más moderadas pero altas. A continuación, se encuentran los países del centro y sur de Europa, concretamente Reino Unido, Portugal y España con 147, 138 y 133, respectivamente. Destacan por ser los de mayor tasa de población reclusa en relación con los de su entorno como Grecia (90), Francia (100), Irlanda (80), Italia (86) y Alemania (76). En los últimos puestos se encuentran los países nórdicos, Dinamarca (61), Finlandia (57) y Suecia (55).

\footnotetext{
${ }^{40}$ Según explotaciones procedentes de INSTITUTE FOR CRIMINAL POLICY RESEARCH, World Prison Brief. 2016, cit. nota $\mathrm{n}^{\mathrm{o}} 1$.

41 Análisis a partir de explotaciones procedentes de diferentes estadísticas del MINISTERIO DEL INTERIOR, cit. nota $\mathrm{n}^{\circ} 6$.
} 
PASTOR, Enrique y TORRES, Manuela. "El sistema penitenciario y las personas privadas de libertad en España desde una perspectiva internacional".

Figura 7: Tasa de población reclusa por 100.000 habitantes en EEUU y países de la UE.

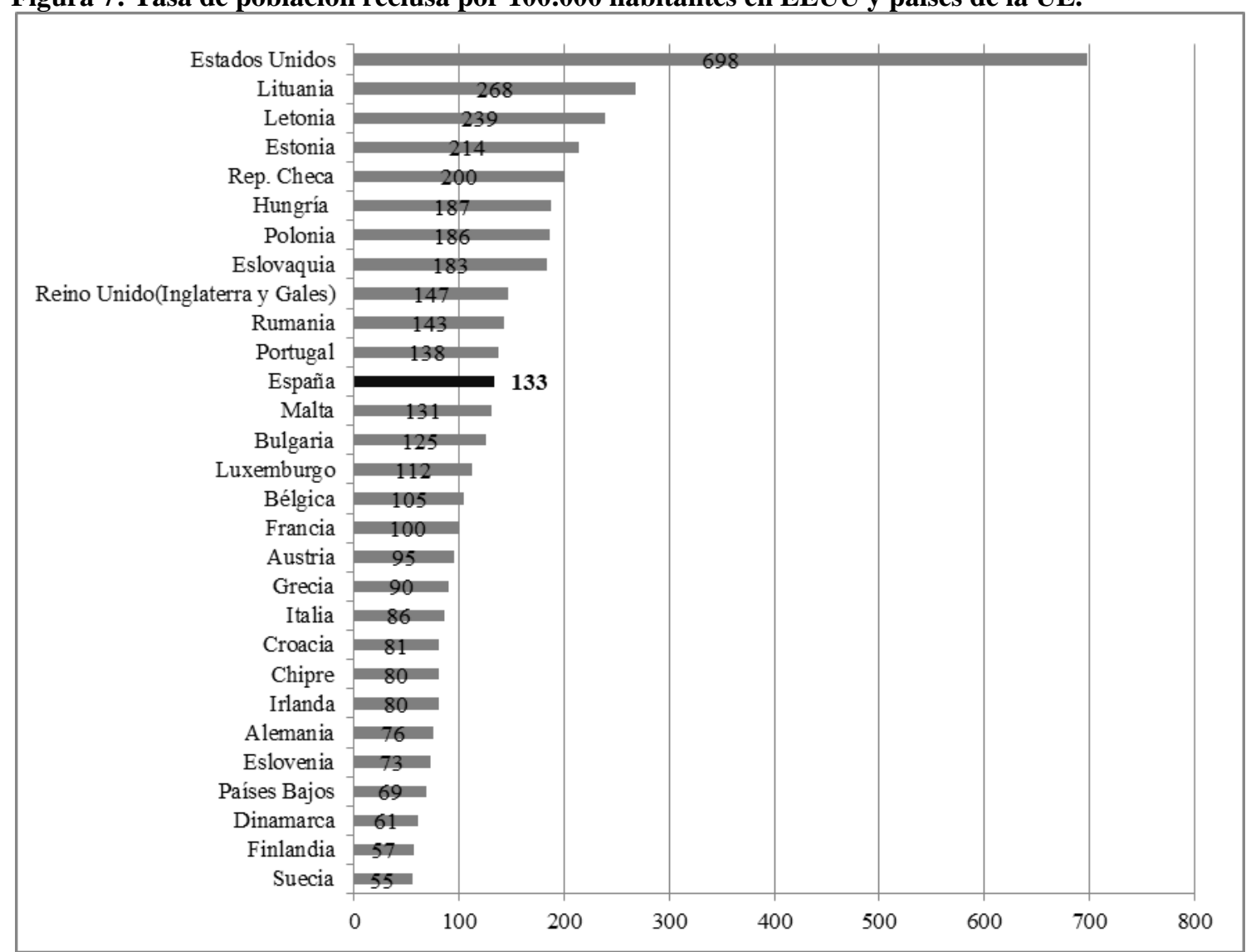

Fuente: Elaboración propia a partir de Institute for Criminal Policy Research ${ }^{42}$.

\subsection{Análisis longitudinal.}

Respecto a la evolución de esta tasa, puede apreciarse en la siguiente figura (8) que España, con un $20.35 \%$ se encuentra entre los países cuya tasa de población reclusa ha aumentado de 2000 a 2014, aunque en un porcentaje menor que la de otros países como Francia $(39,02 \%)$ o Grecia (58.57\%). Observamos, por el contrarío, una diferencia muy acusada respecto de Alemania en la que se ha producido un descenso del 10.59\%. En esta variable, EEUU permanece estable, con un leve aumento del $0.14 \%$. Presentan un incremento superior al $100 \%$ Malta $(134,43 \%)$ y Croacia $(128,88 \%)$. Los países con mayor descenso son Rumania, Estonia, Letonia y Lituania, con el 52,80\%, 32.94\%, 31,39\% y 23,17\%, respectivamente.

\footnotetext{
${ }^{42}$ Según explotaciones procedentes de INSTITUTE FOR CRIMINAL POLICY RESEARCH, World Prison Brief. 2016, cit. nota $\mathrm{n}^{\circ} 1$.
} 
Polít. crim. Vol. 12, No 23 (Julio 2017), Art. 5, pp. 124-150.

[http://www.politicacriminal.cl/Vol_12/n_23/Vol12N23A5.pdf]

Figura 8: Evolución de la tasa de población reclusa por 100.000 habitantes en los países de la UE (20002014) y en EEUU (2000-2013)

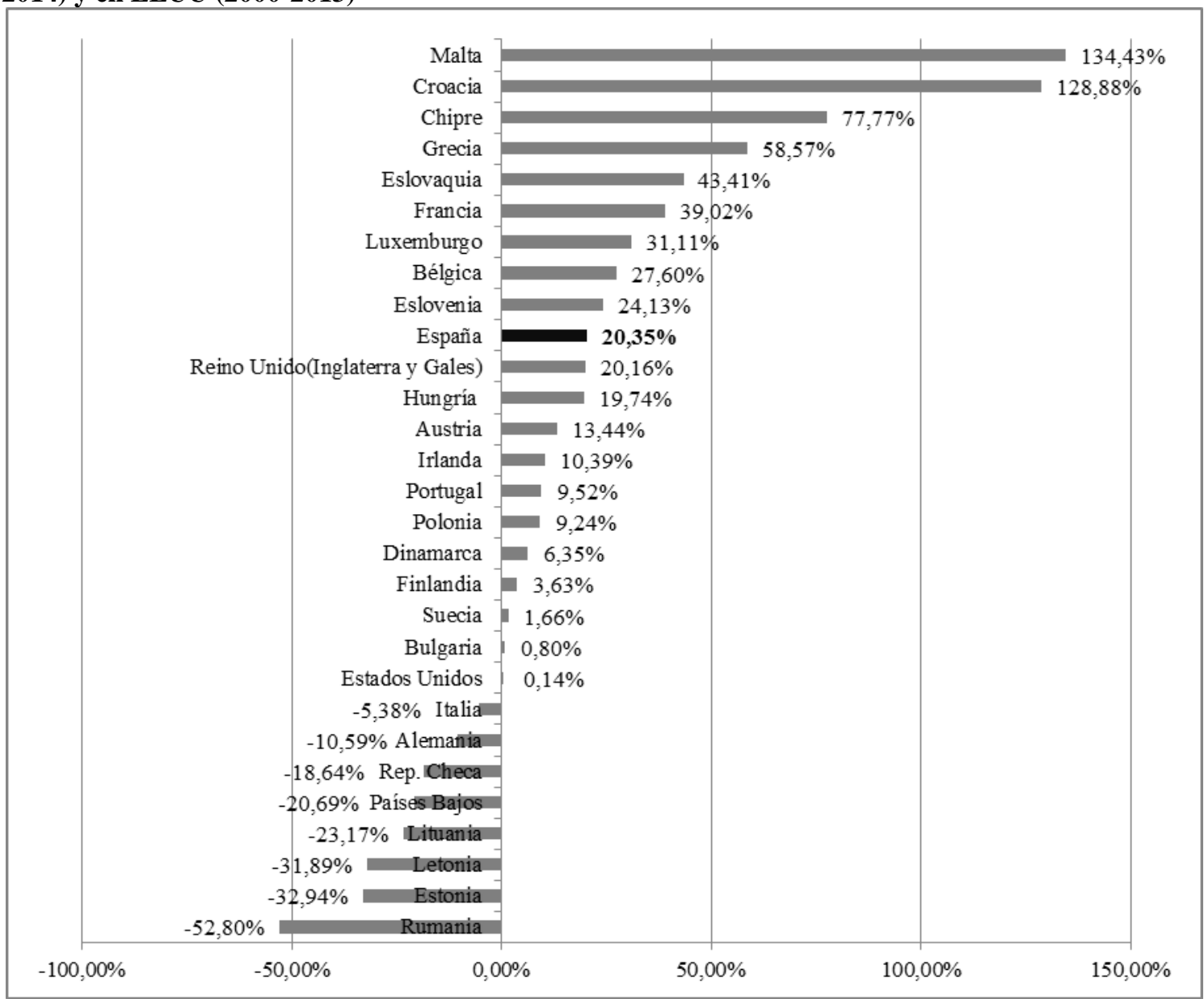

Fuente: Elaboración propia a partir de Institute for Criminal Policy Research ${ }^{43}$.

En cuanto a la tasa de criminalidad, España presenta una de las menores de la UE, concretamente 46.1 delitos por cada 100.000 habitantes, sólo superior a la de Italia $(43,4)$, Portugal $(39,7)$ y Grecia $(29,5)$ y muy inferior a la de países como Suecia $(146,7)$, Reino Unido $(73,8)$ y Alemania $(72,5)$, e inferior a la media europea, situada en $62.8^{44}$. En España esta tasa ha ido descendiendo paulatinamente desde 2002 , cuando se situaba en $52,2^{45}$, hasta la actualidad situado en 43,8 delitos/100.000 habitantes ${ }^{46}$.

\footnotetext{
${ }^{43}$ Análisis estadísticos de INSTITUTE FOR CRIMINAL POLICY RESEARCH, World Prison Brief. 2016, cit. nota $\mathrm{n}^{\circ} 1$.

${ }^{44}$ Según explotaciones estadísticas a partir de SECRETARÍA GENERAL DE INSTITUCIONES PENITENCIARIAS, cit. nota $\mathrm{n}^{\circ} 22$.

${ }^{45}$ A partir de datos procedentes del MINISTERIO DEL INTERIOR. Balance de criminalidad 2013. (2014), en: http://www.interior.gob.es/documents/10180/1207668/balance_2013_criminalidad.pdf/562cc539-4a36470f-8976-7dd305483e5b, [visitado el 22.02.2016].

${ }^{46}$ MINISTERIO DEL INTERIOR. Los índices de criminalidad consolidan su descenso con una caída del $2,8 \%$ en el tercer trimestre del año (2015), en: http://www.interior.gob.es/prensa/noticias//asset_publisher/GHU8Ap6ztgsg/content/id/4992655, [visitado el 28.02.2016].
} 
PASTOR, Enrique y TORRES, Manuela. "El sistema penitenciario y las personas privadas de libertad en España desde una perspectiva internacional".

\subsection{Distribución por sexos.}

La proporción de mujeres en la población penitenciara se encuentra en cifras inferiores al $10 \%$ en todos los países estudiados. EEUU se sitúa a la cabeza con un 9,3\%, seguido de Chipre con un 7,8\%, (país de la UE con más mujeres por cada 100 personas reclusas) y de España con 7.6\%; con porcentajes alejados de otros países del entorno como Francia $(3,3 \%)$, Irlanda (3,9\%), Italia (4\%) y Grecia (5\%). Bulgaria es actualmente el país de la UE con menos población femenina reclusa, con el $3.2 \%$.

\subsection{Población reclusa extranjera.}

En cuanto a la población reclusa extranjera, la UE presenta una media del 21,9\%. España es uno de los países que cuenta con un porcentaje superior a esa media, con el 29,7\%, junto con otros países como Italia, con el 33,2\% y Alemania, con el 27,1\%. Destacan varios países con porcentajes muy elevados, en los que la población reclusa extranjera supera el 50\%: Austria $(50,9 \%)$ y Luxemburgo $(72,3 \%)$. En el lado opuesto, mencionar a Polonia, Rumania, Lituania, Eslovaquia y Letonia, con una población extranjera en prisión entre el $0,7 \%$ y el $1,8 \%$. En esta variable EEUU también se distancia de la UE, pero es este caso con una media muy inferior, ya que tiene 5,5 extranjeros por cada cien reclusos. Precisar que esta cifra se refiere a ciudadanos no estadounidenses que cumplen condena en ese país y no a ciudadanos pertenecientes a minorías étnicas o emigrantes nacionalizados, para los que la situación es muy diferente ${ }^{47}$.

\subsection{Población preventiva.}

El porcentaje medio de personas en situación preventiva respecto de la población reclusa de la UE es del 22,1\%. España, con el $12,5 \%$, se encuentra en un porcentaje 10 puntos inferior a la media europea, lejos de otros países de su entorno, como Italia (33,2\%), Grecia $(26,7 \%)$, Francia $(23,6 \%)$, incluso inferior al de Alemania, situado en el 19\%. Dos países destacan por el alto porcentaje de población preventiva: Luxemburgo con el $43 \%$ y Países Bajos con el 39,9\%. En este caso, EEUU, con el 20,4\%, presenta un porcentaje de población reclusa preventiva muy similar al de la media de la UE.

\subsection{Estancia media en prisión.}

Respecto de la estancia media en prisión, la media en la UE se sitúa en 10.3 meses, cifra superada por numerosos países, entre los que se encuentra España, en quinto lugar, con una media de permanencia de 16 meses. Rumanía, es el país europeo donde las personas están en prisión durante más tiempo, con una media de 25 meses. En nuestro entorno y con medias inferiores a la española, se encuentran Italia con 12,6, Reino Unido con 9,2, Francia

\footnotetext{
${ }^{47}$ Referencia a ciudadanos estadounidenses pertenecientes a minorías, como las personas de origen latino o hispano y afroamericano, que representan alrededor del $60 \%$ de la población reclusa estadounidense, en: http://www.bbc.com/mundo/noticias/2014/04/140311_eeuu_carceles_privadas_reclusos_minorias_rentables_j g, [visitado el 12.02.2016].
} 
Polít. crim. Vol. 12, No 23 (Julio 2017), Art. 5, pp. 124-150.

[http://www.politicacriminal.cl/Vol_12/n_23/Vol12N23A5.pdf]

con 8,8 y Alemania con 8,2 meses. Los países con una permanencia media inferior a 3 meses son Irlanda, Chipre y Suecia con 3, 2,6 y 2 meses, respectivamente ${ }^{48}$.

\subsection{Tasa de ocupación de las prisiones.}

Actualmente, los países con menor tasa de ocupación son los Países Bajos, con el 77\% y Letonia, con el 59,5\%. España, con el 84,2\%, es el séptimo país europeo con menor tasa de ocupación de sus prisiones, lejos de países de nuestro entorno como Francia, con el $115,8 \%$, Portugal, con el $111,9 \%$ y Reino Unido, con el $111 \%$ y cercana a los valores de Alemania y Suecia, ambas con el $83,1 \%$. Entre los países con mayor tasa de ocupación están Hungría, con el 133,8\% y Bélgica, con el 122,7\%.

\subsection{Duración media de las penas y medidas privativas de libertad.}

Según se puede apreciar en la tabla (1) siguiente, son varios los países que tienen una alta tasa de personas cumpliendo penas inferiores a un año, entre ellos, los Países Bajos, con el $44.30 \%$, Alemania con el $43.70 \%$, Francia con el $36.50 \%$ y Bulgaria con el $31.40 \%$. Muy lejos se encuentra España (8.20\%), Grecia (5.90\%), Bélgica (5.70\%) y Rumanía (2.70\%). Por otra parte, un $44.87 \%$ de la población penitenciaria de la UE cumple condenas entre uno y cinco años, sin embargo, sólo el $43.90 \%$ de la población penitenciaria española cumple condenas de esta cuantía. Con un valor más alto que la media europea podemos encontrar a Polonia (56\%), Eslovenia (54.80\%), Hungría (53.90\%) y Croacia $(53.33 \%)$. En el extremo opuesto destaca Grecia con $9.80 \%$, encontrándose el resto de países con valores cercanos a la media.

Respecto a las personas condenadas entre 10 y 20 años, mencionar a Malta con el 23.50\%, Grecia con el $18.80 \%$, Lituania con el $17.80 \%$ y Letonia con el $16.20 \%$. España con el $15.40 \%$, se sitúa cinco puntos por encima de la media europea. Entre los países con menor porcentaje en este intervalo nos encontramos a Alemania (1.20\%), Polonia (3.80\%), Reino Unido $(6.40 \%)$ y Austria (6.70\%).

En cuanto a las condenas superiores a los 20 años, destaca Grecia (18.80\%), con dieciséis puntos por encima de la media europea, situada en el $2.71 \%$. En similar sentido se significan Bélgica (7\%), Malta (6.10\%), Luxemburgo (5.80), Italia (5.10\%) y España, con una cifra que casi duplica la media, concretamente el $4.70 \%$. Por el contrario, y con cifras significativamente inferiores a la media citar a Alemania, donde no consta ninguna condena de estas cuantías, Lituania (0.10\%), Letonia (0.20\%) y Austria, Bélgica y Hungría $(0.30 \%)$.

Por último, entre los países que tienen cadena perpetua ${ }^{49}$, destacar: Reino Unido (10.70\%), Grecia (10.40\%), Irlanda (9.10\%), Finlandia (8.50\%) y Chipre $(5.30 \%)$.

\footnotetext{
${ }^{48}$ Datos contrastados con estudios sobre la materia en AEBI/ DELGRANDE, SPACE I - Council of Europe Annual Penal Statistics: Prison Population. 2015, cit. nota $\mathrm{n}^{\circ} 3$.

${ }^{49}$ En el momento en el que se emitieron estos datos España era uno de los pocos países europeos que no contemplaban esa pena en su Código Penal, actualmente exista la "prisión permanente revisable".
} 
PASTOR, Enrique y TORRES, Manuela. "El sistema penitenciario y las personas privadas de libertad en España desde una perspectiva internacional".

Tabla 1.- Duración media de las penas y medidas privativas de libertad en países de la UE

\begin{tabular}{|c|c|c|c|c|c|c|c|c|}
\hline & - 1 año & 1-5 años & +5-10 años & +10-20 años & +20 años & $\begin{array}{l}\text { Cadena } \\
\text { perpetua }\end{array}$ & Otras & Total \\
\hline Alemania & $43,70 \%$ & $44,60 \%$ & $6,90 \%$ & $1,20 \%$ & $0,00 \%$ & $3,60 \%$ & $0,00 \%$ & $100,00 \%$ \\
\hline Austria & $19,80 \%$ & $52,90 \%$ & $18,30 \%$ & $6,70 \%$ & $0,30 \%$ & $2,00 \%$ & $0,00 \%$ & $100,00 \%$ \\
\hline Bélgica & $5,70 \%$ & $41,90 \%$ & $32,10 \%$ & $10,60 \%$ & $7,00 \%$ & $2,60 \%$ & $0,10 \%$ & $100,00 \%$ \\
\hline Bulgaria & $31,40 \%$ & $46,00 \%$ & $10,60 \%$ & $9,70 \%$ & $0,30 \%$ & $2,00 \%$ & $0,00 \%$ & $100,00 \%$ \\
\hline Chipre & $19,30 \%$ & $34,80 \%$ & $23,90 \%$ & $13,30 \%$ & $3,40 \%$ & $5,30 \%$ & $0,00 \%$ & $100,00 \%$ \\
\hline Croacia & $13,30 \%$ & $53,30 \%$ & $17,90 \%$ & $11,40 \%$ & $4,10 \%$ & - & $0,00 \%$ & $100,00 \%$ \\
\hline Dinamarca & $33,20 \%$ & $43,00 \%$ & $11,40 \%$ & $9,00 \%$ & $0,10 \%$ & $0,90 \%$ & $2,40 \%$ & $100,00 \%$ \\
\hline Eslovaquia & $22,60 \%$ & $42,60 \%$ & $25,10 \%$ & $7,60 \%$ & $1,60 \%$ & $0,50 \%$ & $0,00 \%$ & $100,00 \%$ \\
\hline Eslovenia & $13,00 \%$ & $54,80 \%$ & $19,80 \%$ & $9,20 \%$ & $3,20 \%$ & $0,00 \%$ & $0,00 \%$ & $100,00 \%$ \\
\hline España & $8,20 \%$ & $43,90 \%$ & $27,70 \%$ & $15,40 \%$ & $4,70 \%$ & - & $0,10 \%$ & $100,00 \%$ \\
\hline Estonia & $12,10 \%$ & $48,50 \%$ & $25,10 \%$ & $11,80 \%$ & $0,90 \%$ & $1,60 \%$ & $0,00 \%$ & $100,00 \%$ \\
\hline Finlandia & $17,10 \%$ & $52,10 \%$ & $15,80 \%$ & $6,90 \%$ & $0,00 \%$ & $8,00 \%$ & $0,10 \%$ & $100,00 \%$ \\
\hline Francia & $36,50 \%$ & $41,20 \%$ & $9,60 \%$ & $8,70 \%$ & $3,20 \%$ & $0,80 \%$ & $0,00 \%$ & $100,00 \%$ \\
\hline Grecia & $5,90 \%$ & $9,80 \%$ & $34,50 \%$ & $18,80 \%$ & $18,60 \%$ & $10,40 \%$ & $2,00 \%$ & $100,00 \%$ \\
\hline Hungría & $14,40 \%$ & $53,90 \%$ & $21,80 \%$ & $7,20 \%$ & $0,30 \%$ & $2,40 \%$ & $0,00 \%$ & $100,00 \%$ \\
\hline Irlanda & $10,20 \%$ & $46,60 \%$ & $25,60 \%$ & $8,00 \%$ & $0,50 \%$ & $9,10 \%$ & $0,00 \%$ & $100,00 \%$ \\
\hline Italia & $5,80 \%$ & $42,10 \%$ & $28,70 \%$ & $14,30 \%$ & $5,10 \%$ & $4,00 \%$ & $0,00 \%$ & $100,00 \%$ \\
\hline Letonia & $5,30 \%$ & $38,70 \%$ & $38,20 \%$ & $16,20 \%$ & $0,20 \%$ & $1,40 \%$ & $0,00 \%$ & $100,00 \%$ \\
\hline Lituania & $7,40 \%$ & $49,40 \%$ & $24,00 \%$ & $17,80 \%$ & $0,10 \%$ & $1,30 \%$ & $0,00 \%$ & $100,00 \%$ \\
\hline Luxemburgo & $8,40 \%$ & $49,30 \%$ & $19,60 \%$ & $12,10 \%$ & $5,80 \%$ & $3,10 \%$ & $1,70 \%$ & $100,00 \%$ \\
\hline Malta & $11,60 \%$ & $39,80 \%$ & $16,30 \%$ & $23,50 \%$ & $6,10 \%$ & $2,70 \%$ & $0,00 \%$ & $100,00 \%$ \\
\hline Países Bajos & $44,30 \%$ & $33,10 \%$ & $11,60 \%$ & $7,30 \%$ & $0,50 \%$ & $0,50 \%$ & $2,70 \%$ & $100,00 \%$ \\
\hline Polonia & $26,70 \%$ & $56,00 \%$ & $7,20 \%$ & $3,80 \%$ & $2,30 \%$ & $0,50 \%$ & $0,00 \%$ & $96,50 \%$ \\
\hline Portugal & $6,80 \%$ & $33,40 \%$ & $35,80 \%$ & $14,20 \%$ & $2,90 \%$ & - & $6,90 \%$ & $100,00 \%$ \\
\hline Reino Unido & $9,40 \%$ & $38,10 \%$ & $18,20 \%$ & $6,40 \%$ & $0,60 \%$ & $10,70 \%$ & $16,60 \%$ & $100,00 \%$ \\
\hline Rep. Checa & $10,30 \%$ & $64,20 \%$ & $16,40 \%$ & $7,90 \%$ & $0,70 \%$ & $0,30 \%$ & $0,20 \%$ & $100,00 \%$ \\
\hline Rumania & $2,70 \%$ & $52,50 \%$ & $26,40 \%$ & $14,70 \%$ & $3,20 \%$ & $0,50 \%$ & $0,00 \%$ & $100,00 \%$ \\
\hline Suecia & $21,80 \%$ & $50,00 \%$ & $16,20 \%$ & $8,30 \%$ & $0,30 \%$ & $3,40 \%$ & $0,00 \%$ & $100,00 \%$ \\
\hline Media & $16,67 \%$ & $44,87 \%$ & $20,88 \%$ & $10,78 \%$ & $2,71 \%$ & $2,77 \%$ & $1,17 \%$ & $100,00 \%$ \\
\hline
\end{tabular}

Fuente: Elaboración propia a partir de SPACE I ${ }^{50}$

\section{Análisis y discusión.}

Los resultados de la investigación muestran que la UE y los EEUU presentan realidades penitenciarias muy diferentes entre sí. EEUU cuenta con una población reclusa muy elevada, casi cuatro veces superior a la media europea y una tasa por 100.000 habitantes de 698 personas privadas de libertad, también muy superior a la media de la UE; su población

${ }^{50}$ En la elaboración de la tabla han sido analizados estudios entre otros los publicados por AEBI/ DELGRANDE, SPACE I - Council of Europe Annual Penal Statistics: Prison Population. 2015, cit. nota $\mathrm{n}^{\circ}$ 3. 
Polít. crim. Vol. 12, No 23 (Julio 2017), Art. 5, pp. 124-150.

[http://www.politicacriminal.cl/Vol_12/n_23/Vol12N23A5.pdf]

reclusa del año 2000 al 2013 ha permanecido estable, con un incremento del $0.14 \%$. Asimismo, cuenta con mayor presencia de mujeres entre su población reclusa que cualquier país europeo, aunque con una población reclusa extranjera muy inferior a la media europea.

Respecto a la situación de España, la tasa de población reclusa se sitúa 7 puntos por encima de la media europea y, comparada con las tasas que registran otros países europeos de su entorno, muy elevada. La evolución de esta tasa sigue siendo positiva en un $20,35 \%$ entre 2000 y 2014, aunque a partir de 2009 ésta haya descendido paulatinamente, y con ella el nivel de ocupación de nuestras prisiones, que ha pasado de 141,9\% en 2008 según consta en Space I-2008 51 al 84,2\% actual, evidencia que nos aleja de la etiqueta de "masificación" que soportaban nuestras prisiones. No obstante, esta caída está relacionada con el descenso de las cuantías de las penas impuestas por delitos contra la salud pública y con el aumento de las repatriaciones de ciudadanos extranjeros infractores a partir de las modificaciones sufridas por la Ley de Extranjería, según informa la Fiscalía en su Informe de $2014^{52}$.

España es el segundo país de la UE con mayor población reclusa femenina, duplicando las cifras de Bulgaria, Francia, Polonia, Lituania e Irlanda. Respecto de la población reclusa extranjera, España se sitúa en un valor un $9 \%$ por encima de la media europea. No obstante, la población reclusa preventiva es un 9,6\% inferior a la media europea; aun así, es muy elevado el porcentaje de personas sobre las que pesa el principio de "presunción de inocencia" que se encuentran privadas de libertad a la espera de que ser juzgadas. Podemos afirmar que resulta difícil salir de las prisiones españolas, ya que la estancia media en prisión es muy elevada, casi seis meses superior a la media de la UE, y superior también a la de países de nuestro entorno como Italia, Reino Unido y Francia; además, el 47,80\% de la población reclusa de España se encuentra cumpliendo condenas que podríamos considerar de especial cuantía, o sea, iguales o superiores a cinco años.

El análisis de los datos constata que no existe una relación directa entre la distribución por sexos de la población en general respecto de la reclusa en particular; mientras que en la población el porcentaje de hombres es de 50\%, en la reclusa supera el $92 \%$. Por el contrario, en el caso de las mujeres, el porcentaje que representan respecto a la población reclusa es muy inferior al que tienen respecto a la población, por lo que la población reclusa es en su mayoría masculina, situación que también ocurre en los demás países, y según el Informe ODA 2010/2011, así ha sido en la primera década de este siglo, con una media del $92 \%$ de hombres frente al $8 \%$ de mujeres ${ }^{53}$. Si comparamos estos datos con las cifras de detenciones por imputaciones por infracciones penales por sexo ${ }^{54}$, podemos afirmar que la

\footnotetext{
51 Una de las primeras series de estudios longitudinales sobre la materia pueden encontrarse en AEBI, Marcelo F., y DELGRANDE, Natalia, SPACE I -2008 Council of Europe Annual Penal Statistics: Prison Population, (2010), en: http://wp.unil.ch/space/files/2011/02/SPACE-1_2008 English.pdf, [visitado el 20.01.2016].

52 TORRES-DULCE LIFANTE, Eduardo, Memoria elevada al Gobierno de S. M. Presentada al inicio del Año Judicial por el Fiscal General del Estado, Madrid: Centro de Estudios Jurídicos, 2014.

53 GARCÍA ESPAÑA, Elisa y DÍEZ RIPOLLÉS, José Luis (Dirs.), Realidad y Política Penitenciarias. Informe ODA 2010/2011. España: Tirant lo Blanch, 2012.

${ }^{54}$ De las detenciones por imputaciones por infracciones penales que se produjeron en 2013 (último año del que el Ministerio del Interior ofrece información por sexo), el 86,73\% corresponden a hombres y el 13,27\% a mujeres; de las detenciones que se produjeron por delitos contras las personas, el 91,36 corresponden a
} 
PASTOR, Enrique y TORRES, Manuela. "El sistema penitenciario y las personas privadas de libertad en España desde una perspectiva internacional".

menor presencia de la mujer en prisión se debe a que delinque en menor medida y a que los delitos que comete son menos violentos, por lo que las codenas lo son también en menor cuantía. Podríamos decir que a la cárcel llegan menos mujeres y permanecen en ella menos tiempo.

Desde una perspectiva de género, es conveniente destacar que la inferioridad numérica de la mujer respecto al hombre en prisión genera consecuencia negativas para ésta, ya existen muy pocas prisiones para mujeres, por lo que tienen que ocupar módulos dentro de prisiones de hombres en la que las actuaciones están diseñadas pensando en el género masculino. Siguiendo a Yagüe, podemos afirmar que sufren:

"precariedad de espacios, peores condiciones de alojamiento, lejanía de su entorno familiar y protector, mezcla de perfiles criminales, etc. $\mathrm{Y}$ sobre todo el desconocimiento de las diferentes características, sociales y personales, que las hacen vulnerables a la entrada en el mundo penal y el desentendimiento sus necesidades" ${ }^{25}$.

En cuanto a aquellas mujeres que se encuentran en prisión en compañía de sus hijos menores de tres años, se ha producido una reducción en los centros penitenciarios que disponían de módulos destinados a albergarlas. Así en 2005 eran 9 las cárceles que disponían de este tipo de módulos, mientras, como se ha indicado anteriormente, en la actualidad únicamente existen tres. Esta importante reducción de unidades específicas las aleja más que al resto de mujeres de su entorno socio-familiar, favoreciendo en mayor medida el desarraigo social y la desvinculación familiar. Esta circunstancia es patente en Galicia, Cantabria, Asturias y el País Vasco, comunidades muy alejadas de Madrid, donde se ubica el módulo de madres más cercano.

En coincidencia con estudios al respecto ${ }^{56}$, tampoco existe una relación directa entre la evolución de la población en España y la evolución de la población reclusa. Esta divergencia puede apreciarse claramente en la tasa de población reclusa por 100.000 habitantes, que ha ido elevándose hasta el año 2009, fecha a partir de la cual se ha ido reduciendo progresivamente, aunque todavía sigue siendo elevada. Cabría pensar entonces, que el aumento de la población reclusa está relacionado con el aumento de la delincuencia, sin embargo la delincuencia oficial en España no se ha incrementado durante los últimos años, tal y como se constata en los datos referenciados anteriormente, en los que se observa un descenso progresivo de ésta. Recordar al respecto que España cuenta con una de las menores tasas de criminalidad de la Unión Europea.

Para analizar esta cuestión tendríamos que hacernos dos preguntas, ¿cómo se ha producido el aumento de población reclusa en España? y ¿por qué está sucediendo esto? Respecto a la

hombres y el 8,64\% a mujeres y, de las detenciones que se produjeron por robos con violencia o intimidación, el $87,29 \%$ corresponde a hombres y el $12,71 \%$ a mujeres. Estos datos pueden ampliarse en MINISTERIO DEL INTERIOR, Delincuencia: delitos, faltas, detenciones e imputaciones, y victimizaciones, (2016d), en: http://www.interior.gob.es/web/archivos-y-documentacion/delincuencia-delitos-faltas-detenciones-eimputaciones-y-victimizaciones, [visitado el 25.08.2016].

55 YAGÜE, Concepción, "Mujeres en prisión. Intervención basada en sus características, necesidades y demandas", Revista española de Investigación Criminológica, n. 5 (2007), A1, pp. 1-24, p. 1.

${ }^{56}$ Según estudios recientes de PASTOR SELLER/TORRES TORRES, "La población reclusa”, cit. nota no 4. 
Polít. crim. Vol. 12, № 23 (Julio 2017), Art. 5, pp. 124-150.

[http://www.politicacriminal.cl/Vol_12/n_23/Vol12N23A5.pdf]

primera, podríamos apuntar a los cambios legislativos que se han llevado a cabo. La entrada en vigor en 1996 del actual Código Penal, elevó las penas para determinados delitos y suprimió la redención ordinaria y extraordinaria de las penas, lo que supuso el cumplimiento íntegro de éstas, y por tanto, una mayor estancia en prisión. Posteriormente las reformas del Código Penal por L.O 7/2003 ${ }^{57}$ y L.O. 15/2003 ${ }^{58}$, introdujeron requisitos para el acceso al tercer grado y la libertad condicional, y otras modificaciones que suponían una dilación de la estancia en prisión. De otro lado, comportamientos como la conducción temeraria, la conducción bajo los efectos de bebidas alcohólicas o sin el preceptivo permiso, que antes eran sancionados administrativamente, actualmente lo son penalmente; y comportamientos que antes quedaban en el ámbito de la vida privada han pasado al ámbito público, y a ser constitutivos de delito, como lo es la violencia de género. También contribuyen a este fenómeno, el uso que se le está dando a las penas y medidas alternativas a la privación de libertad, que a pesar de estar incrementándose considerablemente, quizás aún no lo suficiente, así como una escasa aplicación de los mecanismos de reeducación y reinserción social que prevé la ley, tales como la autorización de permisos de salida y la clasificación en tercer grado de tratamiento (régimen abierto), ya que en la ejecución de las penas el grado de tratamiento por excelencia en España, se ha podido constatar que es el segundo grado ${ }^{59}$. Todas estas circunstancias pueden explicar en alguna medida cómo se ha producido el aumento de la población reclusa, pero en un país seguro, como parece que lo es España y en el que la criminalidad desciende ¿por qué ese endurecimiento de las sanciones penales? Para contestar esa pregunta tendríamos que poner nuestra atención en "un fenómeno social muy amplio, y que afecta a una zona importante de las sociedades: el castigo y el mantenimiento del orden" 60 .

En una sociedad como la actual, marcada por la desigualdad económica, los delitos contra la salud pública y contra el patrimonio y el orden socioeconómico constituyen la gran mayoría de los delitos por los que se cumple condena, sin embargo, todos los medios de comunicación prestan una desmesurada atención a la delincuencia, ocupando sus titulares con abundante información sobre asesinatos, violaciones, con los que se alimenta un falso sentimiento de inseguridad ciudadana; de otro lado, han surgido grupos de presión de víctimas que tienen una notable influencia en la sociedad. Todo este sentir de la sociedad se canaliza en masivas demandas de rigor a la hora de legislar y de aplicar la ley. Estas demandas son aprovechadas por los agentes políticos que realizan propuestas para que se refuercen punitivamente las actividades delictivas.

\footnotetext{
${ }^{57}$ ESPAÑA. Ley Orgánica 7/2003, de 30 de junio, de medidas de reforma para el cumplimiento íntegro y efectivo de las penas, Boletín Oficial del Estado, no. 156, de 1 de julio de 2003, (2003a), pp. 41842-41875.

${ }^{58}$ ESPAÑA. Ley Orgánica 15/2003, de 25 de noviembre, por la que modifica la ley Orgánica 10/1995, de 23 de noviembre, del Código Penal, Boletín Oficial del Estado, nº. 283, de 26 de noviembre de 2003 (2003b), pp. 41842-41875.

${ }^{59}$ Estos escenarios pueden ser consultados en CID MOLINÉ, José, "El incremento de la población reclusa en España entre 1996-2006: Diagnóstico y remedios", Revista Española de Investigación Criminológica, n 6 (2008), A2, pp. 1-31, en: http://www.criminologia.net/pdf/reic/ano6-2008/a62008art2.pdf, [visitado el 23.02.2016].

${ }^{60}$ GONZÁLEZ SÁNCHEZ, Ignacio, "Aumento de presos y Código Penal. Una explicación insuficiente", Revista Electrónica de Ciencia Penal y Criminología, $\mathrm{n}^{\circ} 13$ (2011), 4, pp. 1-22, p. 13, en: http://criminet.ugr.es/recpc/13/recpc13-04.pdf, [visitado el 15.01.2016].
} 
PASTOR, Enrique y TORRES, Manuela. "El sistema penitenciario y las personas privadas de libertad en España desde una perspectiva internacional".

"En este contexto, el profesional de la política acuña, frecuentemente, normas que ni solucionan lagunas punitivas, ni se justifican por su necesidad racionalmente valorada, pero permiten al poder político lanzar el mensaje de que se está reaccionando ante las preocupaciones ciudadanas. (...), con especial atención a la realidad española entre los años 2000 y 2004, el conjunto de las reformas penales terminan por desplazar el espacio reservado a las políticas sociales y ensanchan la dimensión punitiva del Estado. El telón de fondo de este escenario es una compleja y progresiva transformación en las bases democráticas de los Estados del Bienestar"61.

Si bien es cierto que en 2010 se produjeron reformas en el código penal que redujeron las penas relacionadas con los delitos por el contra la salud pública, y las dificultades para acceder al tercer grado de tratamiento quedaron reducidas considerablemente, no es menos cierto que el día 1 de julio de 2015 entró en vigor una modificación del Código Penal que lo convierte, a nuestro modo de entender, en una ley más punitiva que la vigente en la última época franquista, y que contempla entre otras medidas desproporcionadas con la realidad actual la "prisión permanente revisable" 62 .

En sintonía con otros estudios al respecto ${ }^{63}$, el perfil más frecuente de la persona privada de libertad en España nos muestra a un varón relativamente joven, condenado por delitos contra la propiedad y clasificado en segundo grado de tratamiento. En cuanto a la edad, destacar que entre los 31 y los 60 años se encuentran las edades en las que más personas están internas en prisión, tanto hombres como mujeres. Respecto a la distribución geográfica, teniendo en cuenta sólo los datos absolutos podríamos pensar que la mayor población reclusa estaría en la comunidad autónoma con mayor número de habitantes, sin embargo, si analizamos la población reclusa de forma relativa, es decir relacionándola con número de habitantes de la Comunidad Autónoma, hemos evidenciado que la distribución de ésta nos está relacionada con esa variable. En cuanto a la situación procesal-penal, el "grueso" se encuentra "penada", pero aun así, existe un porcentaje importante de personas en situación preventiva, o sea que esperan internos en prisión a ser juzgados; no obstante, esta variable no está relacionada con las políticas penitenciarias, sino con decisiones judiciales.

Si realizamos una comparación de tipología delictiva por sexo, podemos afirmar que la principal actividad delictiva de la mujer es contra la salud pública, mientras que en el hombre son los delitos contra el patrimonio, y que sumados los porcentajes de ambos delitos, tantos en hombres como en mujeres, representan la mayoría de la actividad delictiva; el porcentaje de homicidios y sus formas se halla muy igualado en ambos sexos. Por tanto, se aprecia claramente que los delitos por los que más personas cumplen condena son contra la salud pública y contra el patrimonio y el orden socioeconómico, sin embargo, como hemos referido anteriormente, los medios de comunicación llenan sus titulares con

\footnotetext{
${ }^{61}$ PERES NETO, Luis, "El populismo punitivo en España: del estado social al estado penal", Surveillance in Latin America. Vigilancia, segurança e controle social, 2009, pp. 219-245, p.242.

${ }^{62}$ Modificaciones introducidas por Ley Orgánica 1/2015, cit. nota ${ }^{\circ} 21$ y Ley Orgánica 2/2015, de 30 de marzo, por la que modifica la ley Orgánica 10/1995, de 23 de noviembre, del Código Penal, en materia de delitos de terrorismo, Boletín Oficial del Estado, nº.77, de 31 de marzo de 2015 (2015b), pp.27177-27185.

${ }^{63}$ FACAL, "Contextualización", cit. nota no 4 y PASTOR SELLER/TORRES TORRES, "La población reclusa", cit. nota ${ }^{\circ} 4$.
} 
Polít. crim. Vol. 12, № 23 (Julio 2017), Art. 5, pp. 124-150.

[http://www.politicacriminal.cl/Vol_12/n_23/Vol12N23A5.pdf]

los homicidios, violaciones y delitos de violencia de género que se producen en España, deformando la percepción que la sociedad tiene de esta realidad.

Analizando la evolución de la clasificación de las personas penadas en los distintos grados de tratamiento penitenciario entre 2005 y 2015, observamos una situación estática. En cuanto a las clasificaciones en tercer grado, apreciamos que de 2000 a 2011 se produce un aumento superior al 3\%, pero a partir de ahí se inicia un descenso del porcentaje de aplicación de régimen abierto hasta la actualidad. Deducimos por tanto, que los programas específicos que la administración penitenciaria desarrolla para preparar el acceso a la vida en semilibertad ${ }^{64} y$, posteriormente, en libertad, no están consiguiendo el objetivo para el que han sido diseñados. En este sentido Salvador Cutiño realiza un estudio sobre la aplicación de éstos, y afirma que "no se desarrollan con las condiciones que los especialistas consideran adecuadas" "65, pero que la aplicación de algún tipo de tratamiento produce una reducción media del $10 \%$ en los niveles de reincidencia, y abogando por la continuidad en su implementación.

\section{Conclusiones.}

Las realidades penitenciarias de EEUU y de la UE son muy diferentes, tanto en sus actuales condiciones como en la evolución de las mismas. En cuanto a la estructura de la población reclusa en Europa, la situación de los diferentes países parece mantenerse en el tiempo, aunque con ligeras variaciones, ya que una situación muy similar fue descrita por García y Díez $^{66}$, que recogen en su estudio las diferencias existentes entre los países bálticos, los eslavos ex soviéticos y los países del centro y norte de Europa. Analizados estos datos, entendemos que aún no existe una armonización de la legislación en materia penitenciaria en la UE, y creemos, que una vez superada la concepción de unión económica que en principio supuso la UE, ésta debe avanzar hacia la creación un espacio penitenciario europeo que dé uniformidad a las políticas de los estados miembros ${ }^{67}$.

España debería tener una posición cercana a los países del centro de Europa, pero como hemos podido constatar de la investigación, son numerosas las dimensiones de análisis en las que se aleja de ésta. Con una tasa de criminalidad muy inferior a la media europea y a la de países de nuestro entorno, cuenta con una tasa de población reclusa que, a pesar de estar descendido, sigue siendo superior a la tasa media europea y a la de otros países cercanos. El estudio ha verificado que el aumento de la población reclusa no se corresponde con el aumento de población ni con los índices de criminalidad. Por lo tanto, la explicación habría que buscarla en un fenómeno social de apoyo al castigo y el orden, que influye en el endurecimiento de las penas y en la tipificación como delitos de conductas que antes eran

\footnotetext{
${ }^{64}$ Puede consultarse información sobre estos programas en la página oficial del Ministerio del Interior, en: http://www.institucionpenitenciaria.es/web/portal/Reeducacion/ProgramasEspecificos/, [visitado el 24.08.2016].

${ }^{65}$ CUTIÑO RAYA, Salvador, “Algunos datos sobre la realidad del tratamiento en las prisiones españolas”, Revista electrónica de Ciencia Penal y Criminología, $\mathrm{n}^{\mathrm{o}} 17$ (2015), A11, pp. 1-41, p. 34, en: http://criminet.ugr.es/recpc/17/recpc17.html [visitado el 24.08.2016].

${ }^{66}$ GARCÍA ESPAÑA, Realidad y Política Penitenciarias. Informe ODA 2010/2011. cit. nota no 49.

${ }^{67} \mathrm{La}$ situación actual de las políticas penitenciarias en la UE ha sido ampliamente analizada por BARAS GONZÁLEZ, Marcos, El Espacio Penitenciario Europeo, Madrid: Ministerio del Interior, 2008.
} 
PASTOR, Enrique y TORRES, Manuela. "El sistema penitenciario y las personas privadas de libertad en España desde una perspectiva internacional".

sancionadas administrativamente (conducir sin el preceptivo permiso o bajo los efectos del alcohol), que han dado lugar a modificaciones en la legislación, regulando mecanismos que dilatan la estancia en prisión, por ejemplo, la eliminación de la redención de penas por trabajo, el establecimiento de periodos de seguridad para determinados delitos $\mathrm{y}$, recientemente, la prisión permanente revisable. Desde el punto de vista de la aplicación de la legislación punitiva, contribuyen en este sentido el uso desmesurado de la prisión preventiva, la excesiva utilización de la pena de prisión en menoscabo de otras penas y medidas alternativas al ingreso en prisión, como el Trabajo en beneficio de la comunidad, la sustitución y la suspensión de las penas, que pueden ejercer el mismo efecto disuasorio y, a su vez, dar una respuesta de menor exclusión social y con un marcado carácter resocializador a los comportamientos delictivos. Y desde la perspectiva de la ejecución de la pena, la insuficiente aplicación del régimen abierto como forma de cumplimiento de ésta, que es preceptivo para el acceso a la libertad condicional.

En suma, el nuevo desafío de los sistemas penitenciarios modernos es establecer medidas alternativas al ingreso en prisión que realmente logren la inclusión social de las personas afectadas, evitando la reincidencia y la función de segregación y estigmatización que la prisión ejerce. No obstante, la resistencia que la sociedad presenta hacia un sistema penitenciario "sin prisiones", hace necesario un proceso previo de concienciación y educación a nivel general sobre este tema. En espera de que se consolide ese nuevo sistema penitenciario, debe de realizarse una mejora de los programas de tratamiento especializado, así como incrementar el número y la formación de los profesionales que los desarrollan, para que alcancen el objetivo previsto en la LOGP de preparar a la persona para la vida en libertad.

Como se ha podido constatar en el desarrollo del artículo, el contexto penitenciario se encuentra estrechamente vinculado con procesos y situaciones de exclusión, así:

“...la mayoría de las prisiones están llenas de personas procedentes de los márgenes de la sociedad. Muchas de ellas procedentes de entornos tremendamente pobres y de familias desestructuradas; una gran proporción habrán estado desempleados; es posible que los niveles de educación sean bajos; algunos habrán vivido en las calles, sin ninguna red social legítima" ${ }^{, 68}$.

En este sentido, aunque la comisión de un delito implica en última instancia una decisión individual de la persona, y es ésta la que permite a la sociedad atribuirle la responsabilidad penal por ese comportamiento, no hemos de olvidar los condicionantes sociales, económicos, políticos, educativos y culturales que subyacen a la actividad delictiva, que sí son responsabilidad de la sociedad, y que si no son identificados y modificados, no van a dejar de influir negativamente en los individuos; por lo tanto, es necesario que la sociedad realice las reformas estructurales necesarias, así como una labor integral, que contemple prevención, asistencia e integración hacia las personas que se encuentran en prisión y sus familias.

\footnotetext{
${ }^{68}$ COYLE, Andrew, La Administración Penitenciaria en el contexto de los Derechos Humanos. Manual para
} el personal penitenciario, Londres: Centro Internacional de Estudios Penitenciarios, 2009, p. 87. 
Polít. crim. Vol. 12, № 23 (Julio 2017), Art. 5, pp. 124-150.

[http://www.politicacriminal.cl/Vol_12/n_23/Vol12N23A5.pdf]

\section{REFERENCIAS BIBLIOGRÁFICAS}

AEBI, Marcelo F., y DELGRANDE, Natalia, SPACE I -2008 Council of Europe Annual Penal Statistics: Prison Population. (2010), en: http://wp.unil.ch/space/files/2011/02/SPACE-1_2008_English.pdf, [visitado el 20.01.2016].

AEBI, Marcelo F., y DELGRANDE, Natalia, SPACE I - Council of Europe Annual Penal Statistics: Prison Population. (2015), en: http://wp.unil.ch/space/files/2015/02/SPACE-I-2013-English.pdf, [visitado el 20.01.2016].

ARANDA CARBONELL, María José, "Una aproximación práctica a la clasificación penitenciaria", Revista de Estudios Penitenciarios, nº 252 (2006), pp. 37-76.

BARAS GONZÁLEZ, Marcos, El Espacio Penitenciario Europeo, Madrid: Ministerio del Interior, 2008.

BUENO ARÚS, Francisco, "Novedades en el concepto de tratamiento penitenciario", Revista de Estudios Penitenciarios, $\mathrm{n}^{\circ} 252$ (2006), pp. 9-36.

CID MOLINÉ, José, "El incremento de la población reclusa en España entre 1996-2006: Diagnóstico y remedios", Revista Española de Investigación Criminológica, $\mathrm{n}^{\mathrm{0}}$ 6, (2008), A2, pp. 1-31, en: http://www.criminologia.net/pdf/reic/ano62008/a62008art2.pdf, [visitado el 23.0.2.2016].

COYLE, Andrew, La Administración Penitenciaria en el contexto de los Derechos Humanos. Manual para el personal penitenciario, Londres: Centro Internacional de Estudios Penitenciarios, 2009.

CUTIÑ̃ RAYA, Salvador, "Algunos datos sobre la realidad del tratamiento en las prisiones españolas", Revista electrónica de Ciencia Penal y Criminología, $\mathrm{n}^{\mathrm{o}} 17$ (2015), A11, pp. 1-41, en: http://criminet.ugr.es/recpc/17/recpc17.html, [visitado el 24.08.2016].

ESPAÑA. Constitución Española, Boletín Oficial del Estado, n 311 , de 29 de diciembre de 1978 (1978), pp. 29313-19424.

ESPAÑA. Ley Orgánica 1/1979, de 26 de septiembre, General Penitenciaria, Boletín Oficial del Estado, no .239 de 5 de octubre de 1979 (1979), pp. 23180-23186.

ESPAÑA, Real Decreto 1396/1992, de 20 de noviembre, por el que se aprueba el Reglamento de Establecimientos Penitenciarios Militares. Boletín Oficial del Estado, $\mathrm{n}^{\circ}$. 305, de 21 de diciembre de 1992 (1992), pp.43288 43292.

ESPAÑA, Ley Orgánica 10/1995, de 23 de noviembre, del Código Penal, Boletín Oficial del Estado, no 281, de 24 de noviembre de 1995 (1995), pp. 33987-34058.

ESPAÑA. Real Decreto 190/1996, de 9 de febrero, por el que se aprueba el Reglamento Penitenciario, Boletín Oficial del Estado, $n^{\circ}$. 40, de 15 de febrero de 1996 (1996), pp. 5380-5435.

ESPAÑA. Ley Orgánica 7/2003, de 30 de junio, de medidas de reforma para el cumplimiento íntegro y efectivo de las penas, Boletín Oficial del Estado, $\mathrm{n}^{\circ} .156$, de 1 de julio de 2003, (2003a), pp. 41842-41875.

ESPAÑA. Ley Orgánica 15/2003, de 25 de noviembre, por la que modifica la ley Orgánica 10/1995, de 23 de noviembre, del Código Penal, Boletín Oficial del Estado, nº. 283, de 26 de noviembre de 2003 (2003b), pp. 41842-41875. 
PASTOR, Enrique y TORRES, Manuela. "El sistema penitenciario y las personas privadas de libertad en España desde una perspectiva internacional".

ESPAÑA. Real Decreto 840/2011, de 17 de junio, por el que se establecen las circunstancias de ejecución de las penas de trabajo en beneficio de la comunidad y de localización permanente en centro penitenciario, de determinadas medidas de seguridad, así como de la suspensión de la ejecución de las penas privativas de libertad y sustitución de penas, Boletín Oficial del Estado, n 145 , de 18 de junio de 2011 (2011), pp. 62933-62941.

ESPAÑA. Ley Orgánica 1/2015, de 30 de marzo, por la que modifica la ley Orgánica 10/1995, de 23 de noviembre, del Código Penal, Boletín Oficial del Estado, nº 77, de 31 de marzo de 2015 (2015a), pp.27061-27176.

ESPAÑA. Ley Orgánica 2/2015, de 30 de marzo, por la que modifica la ley Orgánica 10/1995, de 23 de noviembre, del Código Penal, en materia de delitos de terrorismo, Boletín Oficial del Estado, no. 77, de 31 de marzo de 2015 (2015b), pp.27177-27185.

EUROSTAT, Estadísticas de población. (2016), en: http://ec.europa.eu/eurostat/statisticsexplained/index.php/Population_statistics_at_regional_level/es, [visitado el 28.02.2016].

FACAL FONDO, Teresa, "Contextualización del trabajo social penitenciario: situación actual”, Revista de Servicios Sociales y Política Social, no 109 (2015), pp.11-20.

GARCÍA ESPAÑA, Elisa y DÍEZ RIPOLLÉS, José Luis (Dirs.), Realidad y Política Penitenciarias. Informe ODA 2010/2011, España: Tirant lo Blanch, 2012.

GEA, María José, "Género, encierro y maternidad. Un acercamiento a la prisión en femenino”, Revista de Servicios Sociales y Política Social, no 109 (2015), pp.51-62.

GENERALITAT DE CATALUNYA, Centres penitenciaris. (2016), en: http://justicia.gencat.cat/ca/ambits/reinsercio_i_serveis_penitenciaris/serveis_peniten ciaris/els_centres_penitenciaris, [visitado el 22.02.2016].

GONZÁLEZ SÁNCHEZ, Ignacio, “Aumento de presos y Código Penal. Una explicación insuficiente”, Revista Electrónica de Ciencia Penal y Criminología, no 13 (2011), A4, pp. 1-22. En: http://criminet.ugr.es/recpc/13/recpc13-04.pdf, [visitado el 15.01.2016].

GUDÍN RODRÍGUEZ-MAGARIÑOS, Faustino, "Introducción”. En GARCÍA VALDÉS, C. (Dir.), Historia de la prisión. Teorías Economicistas: Crítica, Madrid: Edisofer, 1997, pp.1-47.

INSTITUTE FOR CRIMINAL POLICY RESEARCH. World Prison Brief. (2016), en: http://www.prisonstudies.org/world-prison-brief, [visitado el 27.02.2016].

INSTITUTO NACIONAL DE ESTADÍSTICA, Población reclusa hasta 2014. (2015a), en: http://www.ine.es/jaxi/tabla.do?path=/t18/a052/a1998/10/\&file=j10050.px\&type=pca $\underline{\mathrm{xis} \& \mathrm{~L}=0}$, [visitado el 10.02.2016].

INSTITUTO NACIONAL DE ESTADÍSTICA, Cifras de población. (2015b), en: http://www.ine.es/inebaseDYN/cp30321/cp_inicio.htm, [visitado el 25.02.2016].

LEGANÉS GÓMEZ, Santiago, La Evolución de la clasificación penitenciaria. Madrid: Ministerio del Interior, 2005.

MINISTERIO DEL INTERIOR, Balance de criminalidad 2013. (2014). Disponible en: http://www.interior.gob.es/documents/10180/1207668/balance_2013 criminalidad.pd f/562cc539-4a36-470f-8976-7dd305483e5b, [visitado el 22.02.2016].

MINISTERIO DEL INTERIOR, Los índices de criminalidad consolidan su descenso con una caída del 2,8\% en el tercer trimestre del año. (2015), en: http://www.interior.gob.es/prensa/noticias//asset_publisher/GHU8Ap6ztgsg/content/id/4992655, [visitado el 28.02.2016]. 
Polít. crim. Vol. 12, No 23 (Julio 2017), Art. 5, pp. 124-150.

[http://www.politicacriminal.cl/Vol_12/n_23/Vol12N23A5.pdf]

MINISTERIO DEL INTERIOR, Estadística penitenciaria. (2016a), en: http://www.institucionpenitenciaria.es/web/portal/documentos, [visitado el 23.02.2016].

MINISTERIO DEL INTERIOR, Centros penitenciarios. (2016b), en: http://www.institucionpenitenciaria.es/web/portal/centrosPenitenciarios, [visitado el 20.02.2016].

MINISTERIO DEL INTERIOR, Programas específicos de intervención. (2016c), en: http://www.institucionpenitenciaria.es/web/portal/Reeducacion/ProgramasEspecificos I [visitado el 24.08.2016].

MINISTERIO DEL INTERIOR, Delincuencia: delitos, faltas, detenciones e imputaciones, $y$ victimizaciones, (2016d), en: http://www.interior.gob.es/web/archivos-ydocumentacion/delincuencia-delitos-faltas-detenciones-e-imputaciones-yvictimizaciones, [visitado el 25.08.2016].

PASTOR SELLER, Enrique; TORRES TORRES, Manuela, "La población reclusa en España", en: PASTOR SELLER, Enrique; CANO SORIANO, Leticia (Coords.). Políticas e intervenciones ante los procesos de vulnerabilidad y exclusión social de personas y territorios: análisis comparado México-España. Madrid (España): Dykinson y México: UNAM, 2016, pp. 225-244.

PERES NETO, Luis, "El populismo punitivo en España: del estado social al estado penal", Surveillance in Latin America. Vigilancia, segurança e controle social, (2009), pp. 219-245.

SANCHEZ PEREZ, Francisca D. y PASTOR-SELLER, Enrique, "Trabajo social penitenciario: prisión civil "vs" prisión militar", Revista de Servicios Sociales y Política Social, n 109 (2015), pp.73-89.

SECRETARÍA GENERAL DE INSTITUCIONES PENITENCIARIAS, El Sistema Penitenciario Español, Madrid, España: Ministerio del Interior, 2014.

TORRES-DULCE LIFANTE, Eduardo, Memoria elevada al Gobierno de S. M. Presentada al inicio del Año Judicial por el Fiscal General del Estado, Madrid: Centro de Estudios Jurídicos, 2014.

YAGÜE, Concepción, "Mujeres en prisión. Intervención basada en sus características, necesidades y demandas", Revista española de Investigación Criminológica, $\mathrm{n}^{\mathrm{o}} 5$ (2007), A1, pp. 1-24. 